\title{
Financing Constraints, Irreversibility, and Investment Dynamics*
}

\author{
Andrea Caggese \\ Pompeu Fabra University \\ First version: 6 June 2001 \\ This version: 12 August 2006
}

\begin{abstract}
We develop a model of an industry with many heterogeneous firms that face both financing constraints and irreversibility constraints. The financing constraint implies that firms cannot borrow unless the debt is secured by collateral; the irreversibility constraint that they can only sell their fixed capital by selling their business. We use this model to examine the cyclical behavior of aggregate fixed investment, variable capital investment, and output in the presence of persistent idiosyncratic and aggregate shocks. Our model yields three main results. First, the effect of the irreversibility constraint on fixed capital investment is reinforced by the financing constraint. Second, the effect of the financing constraint on variable capital investment is reinforced by the irreversibility constraint. Finally, the interaction between the two constraints is key for explaining why input inventories and material deliveries of US manufacturing firms are so volatile and procyclical, and also why they are highly asymmetrical over the business cycle.
\end{abstract}

JEL classification: D21, E22, E32, G31

Keywords: Financing Constraints, Irreversibility, Investment

${ }^{*}$ I am most grateful to Nobu Kiyotaki for his encouragement and valuable feedback on my research. I would also like to thank Kosuke Aoki, Orazio Attanasio, Steven Bond, Heski Bar-Isaac, Antonio Ciccone, Vicente Cunat, Janice Eberly, Ashok Kaul, Aubhik Khan, Francois Ortalo-Magnė, Steve Pischke, Vincenzo Quadrini, Michael Reiter, Julia Thomas and an anonymous referee for their valuable comments and suggestions on earlier versions of this paper, as well as the participants in the 2004 workshop on "Dynamic Macroeconomics" in Hydra, in the "Capital Markets and the Economy" workshop at the 2003 NBER Summer Institute, in the 2003 EEA meetings in Stockholm, and in the LSE, FMG and UPF seminars. All errors are, of course, my own responsibility. Research support from the Financial Markets Group and from Mediocredito Centrale are gratefully acknowledged. Please, address all correspondence to: andrea.caggese@econ.upf.es or Pompeu Fabra University, Department of Economics, Room 1E58, Calle Ramon Trias Fargas 25-27, 08005, Barcelona, Spain. 


\section{Introduction}

A body of theoretical literature has shown that asymmetric information and contract incompleteness may limit firms access to external finance and thus make them unable to fund profitable investment opportunities. ${ }^{1}$ Over the past 20 years several authors have investigated if financing constraints are an important determinant of the investment at firm level and of the cyclical fluctuations of aggregate investment and output. During the same period other authors have studied the effect of the irreversibility of investment on capital accumulation and aggregate investment dynamics. $^{2}$

The motivation of this paper is that these constraints have always been analyzed in isolation, with very few exceptions (Scaramozzino, 1997 and Holt, 2003). Therefore little is known about the interactions between irreversibility and financing constraints. In this paper we develop a model of firm investment with both irreversibility of fixed capital and borrowing constraints. We show that these constraints interact and reinforce each other, that these interactions amplify the effect of these constraints on firm level and aggregate investment, and that they are important to understand the dynamics of investment over the business cycle.

Our model has three distinctive features. First, output is produced by a risk neutral profit maximizing firm which operates a concave risky technology using two complementary factors of production, fixed and variable capital. Second, new investment in fixed capital takes one period to produce output, while new investment in variable capital is immediately productive. Moreover, the fixed capital stock cannot be disinvested unless the whole business is sold, while variable capital is fully reversible. Third, the firm's only source of external finance is debt secured by collateral assets.

We show that the irreversibility and the financing constraints interact and their effects amplify each other. This amplification is both static and dynamic. The static component is intuitive. If a firm is financially constrained then it can only invest if it has available internal funds. Therefore a negative exogenous shock that reduces the financial wealth of a firm also reduces its investment capacity. If fixed capital is irreversible, then this reduction is absorbed by a reduction in variable capital investment. The dynamic component is less intuitive but not less important. It implies that a binding irreversibility constraint greatly increases the intensity of future financing constraints. As an example, consider a firm which faces a persistent negative productivity shock and expects negative profits for some periods. Fixed capital is inefficiently high because of the irreversibility constraint, and this reduces profits, the return on capital and the market value of the firm. Suppose now that the firm also faces capital market imperfections. Negative profits reduce the financial wealth of the firm and increase the probability of facing a binding financing constraint in the future. If the negative shock is very persistent, financial wealth may be reduced up to the point where both constraints are simultaneously binding. In this case fixed capital is inefficiently high but also variable capital is inefficiently low. The unbalanced use of the two factors of production

\footnotetext{
${ }^{1}$ Stiglitz and Weiss (1981), Besanko and Thakor (1986), Milde and Riley (1988), Hart and Moore (1998), Albuquerque and Hopenhayn (2004).

${ }^{2}$ See Caballero (1999) for a review of the literature about investment with real constraints and Hubbard (1998) for a review of the literature about investment with financing constraints.
} 
increases losses and further reduces financial wealth and variable capital investment. When the bad period ends and productivity starts to increase, the firm, if it managed to avoid default, is very cautious about investing in fixed capital. This is because it fears the consequences of future irreversibility and financing constraints. Therefore the interaction between these constraints increases the volatility of variable capital during downturns and reduces the volatility of fixed capital during upturns.

We use this model with interacting financing and irreversibility constraints to explain why inventories are very volatile and why they respond asymmetrically over the business cycle. The high volatility of inventories has been documented by Ramey (1989), Blinder and Maccini (1991) and Ramey and West (1999). Moreover, the same authors show that inventory investment is procyclical, and that the drop in inventories accounts for a large part of the GDP decline in recessions. This indicates that inventory dynamics are important to understand business cycle fluctuations. However it remains an open question if there is more commovement between inventories and output during recessionary than during expansionary periods. In the empirical section of the paper we provide new evidence on this issue. We analyze the dynamics of output, material deliveries and input inventories of several two digits durable goods manufacturing sectors, using quarterly data from 1962 to 1996. We find that both input inventories and deliveries are significantly more procyclical around recessionary than expansionary periods. In almost all the sectors considered, the procyclicality of inventories completely disappears if we only analyze periods in which output is above its trend.

In order to explain this empirical evidence we calibrate our model to simulate the behaviour of an industry with many heterogeneous firms. We model material deliveries and input inventories as the gross flow and the end of the period stock of variable capital respectively. We simulate several artificial industries, over many periods, with and without financing imperfections and irreversibility of fixed capital. The simulated data show that the interactions between the financing and the irreversibility constraint are essential to generate the high volatility of inventories and deliveries relative to fixed capital, as well as their asymmetric behavior in the different phases of the business cycle.

Four recent papers adopt a similar approach to our paper, and analyze an economy with heterogenous firms where financing constraints are binding for a fraction of them in equilibrium: Cooley and Quadrini (2001), Cooley, Marimon and Quadrini (2004), Gomes (2001) and Jermann and Quadrini (2006). In particular Cooley and Quadrini (2001) show that financing imperfections in a model of industry dynamics explain a stylized fact regarding growth dynamics of firms which is not explained by models based only on technological shocks. Moreover our paper is also related to the irreversibility literature, and in particular to Bertola and Caballero (1994), Abel and Eberly (1999) and Veracierto (2002). Finally, our paper is related to Holt (2003), who analyses the effects of the interactions between the financing and the irreversibility constraints on the dividend policy along the life cycle pattern of firms.

Yet, our paper is substantially different from all those above. We focus on the interactions between financing and irreversibility constraints as well as on business cycle dynamics rather than growth dynamics of firms. We model theoretically and quantify with simulations a precautionary 
effect of future expected financing constraints on risky investment. We model theoretically an amplification effect between the irreversibility and the financing constraint and show that such effect is essential for explaining the cyclical fluctuations of variable capital in the US manufacturing sector.

The paper is organized as follows: section 2 illustrates the empirical evidence regarding the dynamics of input inventories and deliveries in the US manufacturing sector; section 3 illustrates the theoretical model; section 4 compares the empirical evidence with the simulation results; section 5 presents the conclusions.

\section{Summary of the empirical evidence}

The aim of this section is twofold. First, we will analyze the dynamics of input inventories in the durable manufacturing sector. Ramey and West (1999) show that inventory investment is procyclical, and that even though the stock of inventories at the economywide level is small relative to GDP, the reduction in inventories account for a large part of the decline in GDP during recessions. One explanation of this evidence is that inventories generally exhibit very high short term volatility (Hornstein, 1998), and there is nothing specific about the behavior of inventories during recessions with respect to the other phases of the business cycle. If this is true, then we should observe that inventory investment increases as sharply (relative to sales) during upturns as it decreases during downturns. In this section we will show that this is not the case for the input inventories in the US manufacturing sector, which are significantly more procyclical during downturns than upturns periods. This happens both for the whole of the manufacturing sector and for single two digits durable manufacturing industries. We focus on input (materials and work in progress) rather than output inventories, because Ramey (1989), Blinder and Maccini (1991) and Humpreys, Maccini and Schuh (2001) show that input inventories are larger and much more volatile than finished goods inventories, especially in the durable goods sectors.

Second, we will show that the procyclicality and asymmetric behavior of inventory investment is always mirrored by a similar procyclicality and asymmetric behavior of material deliveries. In order to explain this empirical evidence, in the next sections we will model variable capital as a factor of production. We will interpret the gross investment in variable capital as the flow of deliveries, and the net change in the end of the period stock of variable capital as the investment in input inventories. Following Humpreys, Maccini and Schuh (2001) we define deliveries as follows:

$$
\text { deliveries }_{y, q}=\text { usage of materials }_{y, q}+\Delta \text { input inventories }_{y, q}
$$

where $y$ denotes the year (from 1962 to 1996) and $q$ denotes the quarter. Input inventories

are materials plus work in progress. Since quarterly data about the usage of materials are not available, we estimate them as follows:

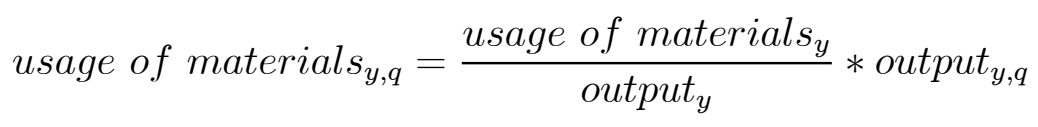

This calculation should be sufficiently accurate since the ratio between usage of materials and output is fairly stable in the short term. In tables 1-3 we illustrate the volatility, procyclicality, 
and asymmetric behavior of material deliveries and input inventories. Table 1 shows the main statistics for the two digits durable manufacturing sectors for which the Bureau of the Census provides detailed historical data. ${ }^{3}$ Industry statistics confirm the empirical evidence, documented by Humpreys, Maccini and Schuh (2001) for the total manufacturing sector, that input inventories are more volatile than finished goods inventories. Moreover deliveries are more volatile than sales in all sectors. The last two columns show that both investment in input inventories and deliveries are procyclical. ${ }^{4}$ The fact that the high volatility and procyclicality of input inventories has a direct counterpart in the volatility and procyclicality of the flow of material deliveries is already noted by Humpreys, Maccini and Schuh (2001). Using annual data about the durable goods manufacturing sector, they show that input inventories are very volatile and procyclical mainly because deliveries drop more than usage of materials during downturns and increase more during upturns.

The next three tables answer the following question: is such procyclicality uniform in the different phases of the business cycle? Tables 2 and 3 provide a negative answer to this question. The first half of Table 2 shows the correlation between $\frac{\Delta \text { inventories }_{t}}{\text { salest }_{t}}$ and sales $_{t}$ separately for different sub-periods. This correlation is significantly positive in the periods in which sales are below their trend, while is not significantly different from zero in the periods in which sales are above their trend. This is true for the total of the manufacturing sector and for 5 out of 7 two digits sectors. Moreover this correlation is larger when detrended sales are decreasing than when they are increasing. The second half of table 2 provides a similar picture regarding the procyclicality of deliveries.

These statistics are consistent with the fact that the drop in inventories accounts for a large fraction of the drop of GDP during recessions. They also show that the asymmetric behavior of input inventories is mirrored by the one of material deliveries. In the next section we will show that the interaction between the financing and the irreversibility constraint generates firm dynamics consistent with this empirical evidence. The explanation provided by our theoretical model is based on the following intuition. At the beginning of a downturn the negative aggregate productivity shock implies that some firms would like to downsize their fixed assets, but they are prevented to do so by the presence of the irreversibility constraint. As the downturn continues and productivity and revenues worsen, some of these firms may also have a binding financing constraint, and hence they may be forced to reduce their investment in variable capital. If this explanation is correct, we expect that the elasticity of deliveries to sales increases conditional on a sequence of negative shocks. Table 3 confirms this. It shows the estimated elasticity of deliveries to sales conditional on the number of periods of subsequent reduction or increase in detrended real sales. During periods of contraction in sales we observe that in 5 out of 7 sectors the elasticity tends to increase conditional on the contraction lasting longer. This is especially true for sectors 34,35 , and 38 . These sectors are also those with the highest degree of asymmetry

\footnotetext{
${ }^{3}$ Source: M3 survey (http://www.census.gov/indicator/www/m3/hist/m3bendoc.htm).

${ }^{4}$ The correlation coefficients regarding inventory investment are smaller in absolute values than the similar coefficients estimated by Ramey and West (1999). This is due to some differences in the way we compute the statistics. We consider durable manufacturing sectors and input inventories while Ramey and West consider the whole of domestic sales and total inventories. We apply the HP filter while Ramey and West apply a linear trend.
} 
in the procyclicality of input inventories and deliveries (see table 2). The same is not true during periods of expansion in sales. Here the elasticity of deliveries does not have any clear increasing or decreasing pattern.

Finally, our theory predicts that financing constraints are an essential factor to generate the asymmetry in the dynamics of input inventories and deliveries. If we accept the view that small firms face tighter constraints than large firms, then we should observe that such asymmetry is stronger for smaller rather than larger firms. Unfortunately we do not have the availability of data disaggregated in the size dimension. Nonetheless the size distribution of the two digits manufacturing sectors is consistent with this prediction. Apart from sector SIC 32, which does not show any significant procyclicality of deliveries in the first place, The three sectors that showed the highest degree of asymmetry in the procyclicality of deliveries and input inventories are also those with the highest density of small firms. The percentage of total payroll from firms smaller than 50 employees is equal to $41 \%, 24 \%$ and $8 \%$ in sectors SIC 34, SIC 35 and SIC 38 respectively. Conversely the same percentage is as small as $4.7 \%$ for the SIC 36 sector, the only one in which the asymmetry goes in the opposite direction.

\section{The model}

In this section we develop a model that studies the interactions between financing and irreversibility constraints. We consider an industry populated by many firms. Each firm chooses investment in fixed and variable capital in order to maximize the expected discounted sum of future dividends. As all firms have access to the same risky technology, we will describe and solve the optimal investment problem of one generic firm. $k_{t}$ and $l_{t}$ are respectively the stock of fixed and variable capital. Variable capital represents variable inputs such as raw materials and work in progress, while fixed capital represents fixed inputs such as plant and equipment. For simplicity, labour is not considered in the analysis. However, the inclusion of an additional factor of production would not affect the results. Output $y_{t}$ is produced according to a Cobb-Douglas production function:

$$
y_{t}=e^{\theta_{t}} k_{t}^{\alpha} l_{t}^{\beta} \text { with } \alpha>0 ; \beta>0 ; \alpha+\beta<1
$$

$\theta_{t}$ is a stationary autoregressive stochastic process representing the productivity shock. Variable capital $l_{t}$ is immediately productive, and is reversible. Fixed capital purchased at time $t$ takes one period to become productive and once installed it cannot be liquidated unless the whole of the assets is sold. This means that, if the firm continues the activity in period $t$, fixed capital $k_{t+1}$ is subject to the following irreversibility constraint:

$$
k_{t+1} \geq\left(1-\delta_{k}\right) k_{t}
$$

$\delta_{k}$ is the depreciation rate of fixed capital. Constraint (2) is justified by the fact that in many industries plant and equipment do not have a secondary market because they cannot be easily converted to other productions. It is also consistent with the empirical evidence from a large sample of US manufacturing plants analyzed by Caballero, Engel and Haltiwanger (1995). Moreover, constraint (2) implies that fixed capital is fully irreversible. Another possibility would 
be to assume partial irreversibility (fixed capital has a resell price lower than its value in the firm). As long as the wedge between the selling price and the internal value is not negligible, both full and partial irreversibility would generate similar qualitative results.

We introduce financial markets imperfections by assuming that equity finance and risky debt are not available. Moreover we follow other studies, such as Kiyotaki and Moore (1997), in assuming that collateralized debt is the only source of external funding. We assume that at time $t$ the firm can borrow (and lend) one period debt, with face value $b_{t}$, at the market riskless rate $r$. A positive (negative) $b_{t}$ indicates that the firm is a net borrower (lender). The amount of borrowing is limited by the following constraint:

$$
b_{t} \leq \tau_{k} k_{t}+\tau_{l} l_{t}
$$

$\tau_{k}$ and $\tau_{l}$ are the shares of fixed and variable capital that can be used as collateral:

$$
\begin{gathered}
\tau_{k} \leq\left(1-\delta_{k}\right)^{2} \\
\tau_{l} \leq 1-\delta_{l}
\end{gathered}
$$

$\delta_{l}$ is the depreciation rate of variable capital. Fixed capital is accepted as collateral because constraint (2) does not apply when the whole of the assets are liquidated. Constraints (4) and (5) holding with equality imply that the end of period $t$ residual capital is fully collateralisable. ${ }^{5}$ In the case of constraint (4) the term $1-\delta_{k}$ is squared because at the beginning of period $t$ capital $k_{t}$ has already depreciated at the rate $\delta_{k}$ (see equation 8 ), and therefore at the end of period $t$ the residual value of one unit of $k_{t}$ is equal to $\left(1-\delta_{k}\right)^{2}$.

The timing of the model is the following: the firm inherits from time $t-1$ the fixed capital $k_{t}$ and the net worth $w_{t}$. At the beginning of period $t$ the shock $\theta_{t}$ is realized, and the firm can either liquidate or continue activity. If the firm is liquidated its assets are sold and its net worth $w_{t}$ is distributed as dividends. If the firm continues activity it pays the fixed cost $F>0$ and borrows one period debt with face value $b_{t}$, receiving the discounted value $b_{t} / R$. The net worth $w_{t}$ plus the new borrowing $b_{t} / R$ are allocated between dividends, variable capital and fixed capital:

$$
\begin{gathered}
d_{t}+k_{t+1}+l_{t}=w_{t}+\frac{b_{t}}{R}-F \\
d_{t} \geq 0
\end{gathered}
$$

\footnotetext{
${ }^{5}$ Constraints (4) and (5) holding with disequality are equivalent to assume that the firm can "steal" a $(1-\tau)$ fraction of the residual value of capital. To assume that $l_{t}$ is collateralisable is equivalent to assume that the firm is given short term trade credit by its suppliers, who then discount such credit at a bank, which is willing to assume the liability because this is secured by the value of variable capital. Regarding fixed capital, the results of the model are not sensitive to whether we assume $k_{t}$ or $k_{t+1}$ to be available as collateral in period $t$. Therefore we chose the more realistic assumption. $k_{t}$ is phisical capital existing at the beginning of time $t$, and can be observed by the lenders at the time they lend the funds. Conversely $k_{t+1}$ is fixed capital that will be in place only at the end of period $t$.
} 
$d_{t}$ are the dividends distributed at time $t$. After producing the firm repays the debt $b_{t}$ at the end of the period. Therefore residual net worth at the end of period $t$ is: ${ }^{6}$

$$
w_{t+1}=y_{t}-b_{t}+\left(1-\delta_{k}\right) k_{t+1}+\left(1-\delta_{l}\right) l_{t}
$$

The fixed cost $F$ ensures that on average a significant fraction of firms earn negative profits. In addition to generating realistic dynamics of revenues and profits, this assumption ensures that a positive fraction of firms have both the financing and the irreversibility constraint binding. In the next section we will show that the interaction between the two constraints is essential for the results obtained in the simulations of the model. Furthermore, the timing assumptions in equations (6) and (8) imply that fixed capital takes two period to generate revenues. This is because fixed capital purchased at time $t-1$ generates output in period $t$, but $y_{t}$ cannot be used to finance period $t$ investment, because it enters the law of motion of wealth at time $t+1$ (see equation 8). This timing assumption is necessary because if we allow $y_{t}$ to enter the law of motion of wealth at time $t$, then equation (6) would imply that variable capital investment could be paid with its own revenues. In this case financing constraints would be binding only for a negligible share of firms in the simulated industries. ${ }^{7}$

Liquidation at the beginning of period $t$ can happen for two different reasons: i) exogenous liquidation, with probability $1-\gamma$. This ensures that the distribution of firms does not degenerate to the point where all firms are very wealthy and no one is financially constrained. ii) Voluntary liquidation. After observing $\theta_{t}$, the firm decides to liquidate before paying the fixed cost $F$ if the net present value of continuing activity is lower than the liquidation value of the assets of the firm. In theory the contemporaneous presence of the financing and the irreversibility constraint can also cause an endogenous "inefficient" liquidation where a firm is forced to sell the business in order to repay the debt, even though the business has a positive net present value. In practice, however, inefficient liquidation is never part of the set of optimal choices conditional on the set of parameters we use for the simulations.

We formulate now the intertemporal maximization problem. We denote the expected value of the firm at time $t$, after $\theta_{t}$ is realized, and conditional on not liquidating in period $t$, by $V_{t}^{\text {stay }}\left(w_{t}, \theta_{t}, k_{t}\right)$, where $w_{t}, \theta_{t}$ and $k_{t}$ are the three state variables of the problem:

$$
V_{t}^{\text {stay }}\left(w_{t}, \theta_{t}, k_{t}\right)=\max _{l_{t}, k_{t+1}, b_{t}} d_{t}+\frac{1}{R} E_{t}\left[V_{t+1}\left(w_{t+1}, \theta_{t+1}, k_{t+1}\right)\right]
$$

$V_{t+1}\left(w_{t+1}, \theta_{t+1}, k_{t+1}\right)$ is defined as follows:

$$
V_{t+1}\left(w_{t+1}, \theta_{t+1}, k_{t+1}\right)=\gamma S_{t+1} V_{t+1}^{\text {stay }}\left(w_{t+1}, \theta_{t+1}, k_{t+1}\right)+\left(1-\gamma S_{t+1}\right) w_{t+1}
$$

\footnotetext{
${ }^{6}$ Equations (1) and (8) imply that one unit of installed fixed capital $k_{t+1}$ is fully productive in period $t+1$, while it's market value is reduced by the depreciation rate $\delta_{k}$.

${ }^{7}$ This is because variable capital investment, $l_{t}-\left(1-\delta_{l}\right) l_{t-1}$, is on average much larger than fixed capital investment, $k_{t+1}-\left(1-\delta_{k}\right) k_{t-1}$. In the calibration of the model with quarterly data, $l_{t} / k_{t+1}$ is on average around $1, \delta_{k}$ around $3 \%$ and $\delta_{l}$ around $50 \%$.
} 
$S_{t}$ is a binary variable. It is equal to one if both the following conditions are satisfied:

$$
\begin{gathered}
V_{t}^{\text {stay }}\left(w_{t}, \theta_{t}, k_{t}\right)>w_{t} \\
\text { and } \\
w_{t}-\left[\left(1-\delta_{k}\right)-\frac{\tau_{k}}{R}\right] k_{t} \geq F
\end{gathered}
$$

and is equal to zero otherwise, indicating that the firm is liquidated. Condition (12) rules out inefficient liquidation, because it ensures that a firm with positive net present value also has enough resources to pay the debt and to continue activity. This condition is determined using equation (6) to substitute $b_{t}$ in the collateral constraint (3) and then substituting $d_{t}=l_{t}=0$ and $k_{t+1}=\left(1-\delta_{k}\right) k_{t} .^{8}$

The firm's problem is defined by equation (9) subject to constraints (2), (3), (6) and (7). The solution to the problem is obtained using a numerical method, and is illustrated in detail in appendix A. A unique solution to this problem may not exist in general, because equation (10) implies that $V_{t+1}$ may not be concave. However for the sets of parameter values chosen for the simulations presented in the next sections we have verified, after solving the problem, that the computed function $E_{t}\left[V_{t+1}\left(w_{t+1}, \theta_{t+1}, k_{t+1}\right)\right]$ is concave in $\left(w_{t}, \theta_{t}, k_{t}\right)$, and therefore also the function $V_{t}^{\text {stay }}\left(w_{t}, \theta_{t}, k_{t}\right)$ is concave, and the solution found is thus unique.

In the remaining parts of this section we provide a description of the first order conditions of the problem in the special case when endogenous exit never happens in equilibrium $\left(S_{t}=1\right.$ for any $t$ ). This simple case is useful to illustrate the effects of the interactions between the financing and the irreversibility constraint on investment decisions. We substitute $S_{t}=S_{t+1}=1$ and $V_{t}=V_{t}^{\text {stay }}$ in equations (9) and (10), obtaining:

$$
V_{t}\left(w_{t}, \theta_{t}, k_{t}\right)=\max _{l_{t}, k_{t+1}, b_{t}} d_{t}+\frac{1}{R} E_{t}\left[\gamma V_{t+1}\left(w_{t+1}, \theta_{t+1}, k_{t+1}\right)+(1-\gamma) w_{t+1}\right]
$$

Let $\mu_{t} \lambda_{t}$ and $\phi_{t}$ be the Lagrangian multipliers associated to the constraints $(2),(3)$ and (7). Also let $\pi_{t+1}$ be the value at the beginning of period $t+1$ of the gross economic profits realized by the firm during period $t$ :

$$
\begin{gathered}
\pi_{t+1}=y_{t}-\Lambda_{t+1} \delta_{k} k_{t}-\delta_{l} l_{t}-R F \\
\Lambda_{t+1}=\frac{R}{\gamma} \frac{1+\gamma \phi_{t}}{1+\gamma \phi_{t+1}}
\end{gathered}
$$

\footnotetext{
${ }^{8}$ Condition (12) implies that $w_{t}$ is always large enough so that, by setting $l_{t}, d_{t}$ and $k_{t+1}$ as low as possible, the firm is always able to satisfy the budget constraint. This condition is violated if $w_{t}$ is low enough. In order to see this, we substitute $w_{t}$ in condition (12) using equation (8), and we consider the "worst case scenario" in which the firm was lacking the funds to invest in variable capital in the previous period: $y_{t-1}=0, l_{t-1}=0, b_{t-1}=\tau_{k} k_{t-1}$ and $k_{t}=\left(1-\delta_{k}\right) k_{t-1}$. In this case condition (12) becomes:

$$
F \leq \tau_{k}\left[\frac{1}{R}\left(1-\delta_{k}\right)-1\right] k_{t-1}
$$

If $\tau_{k}$ is greater than zero, condition (13) cannot be satisfied even if $F=0$. But with $F=0$ any firm, no matter how small its scale of activity is, has a positive net present value of the discounted stream of future profits. Therefore condition (13) implies that in the worst case scenario a firm may decide to liquidate even though, if capital was reversible, it would have been profitable to continue.
} 
The cost of fixed capital depreciation, $\delta_{k} k_{t}$, is multiplied by the term $\Lambda_{t+1}$ which takes into account that the cost of capital is affected by the shadow value of money in period $t+1$ relative to the shadow value in period $t . \Lambda_{t+1}$ is inversely related to $\gamma$ because with probability $1-\gamma$ the firm liquidates at the beginning of period $t$ before the installed capital $k_{t}$ can be used for production. Substituting $d_{t}$ in equation (14) using equation (6) and taking the first order conditions of equation (14) with respect to $b_{t}, l_{t}$ and $k_{t+1}$, it is possible to show that the solution of the problem is given by the optimal sequence of $\left\{k_{t+1}, l_{t}, b_{t}, d_{t}, \lambda_{t}, \mu_{t}, \phi_{t} \mid k_{t}, w_{t}, \theta_{t}, \Theta\right\}_{t=0}^{\infty}$ which satisfies equations (2), (16), (17), (18) and (19), plus the standard complementary slackness conditions on $\lambda_{t}, \mu_{t}$ and $\phi_{t}$ :

$$
\begin{gathered}
\phi_{t}=R \lambda_{t}+\gamma E_{t}\left(\phi_{t+1}\right) \\
{\left[1+\gamma E_{t}\left(\phi_{t+1}\right)\right]\left(\pi_{t+1}^{l}-r\right)=\left(R-\tau_{l}\right) R \lambda_{t}} \\
\frac{\gamma}{R} E_{t}\left[\left(1+\gamma \phi_{t+2}\right) \pi_{t+2}^{k}\right]-\left(1+\phi_{t}\right) r=R \lambda_{t}-\gamma \tau_{k} E_{t}\left(\lambda_{t+1}\right)-R \mu_{t}+\gamma\left(1-\delta_{k}\right) E_{t}\left(\mu_{t+1}\right) \\
d_{t}+\left(1-\frac{\tau_{l}}{R}\right) l_{t}+k_{t+1} \leq w_{t}+\frac{\tau_{k}}{R} k_{t}
\end{gathered}
$$

$\pi_{t+2}^{k}=\frac{\partial \pi_{t+2}}{\partial k_{t+1}}$ and $\pi_{t+1}^{l}=\frac{\partial \pi_{t+1}}{\partial l_{t}}$ are the marginal gross profits of fixed and variable capital respectively. ${ }^{9}$ Equation (19) combines the budget constraint (6) and the collateral constraint (3) and implies that the downpayment necessary to finance $k_{t+1}, l_{t}$ and $d_{t}$ must be lower than the net wealth of the firm plus the additional funds borrowed using $k_{t}$ as collateral. $\left(1-\frac{\tau_{l}}{R}\right)$ is the downpayment necessary to buy one unit of variable capital. $\lambda_{t}$ is positive when the financing constraint is binding in period $t$ (equation 19 is holding with equality), and is equal to zero otherwise. $\phi_{t}$ is positive when the financing constraint is binding in period $t$ or has some probability to bind in the future. This can be easily seen by iterating forward equation (16):

$$
\phi_{t}=R \sum_{j=0}^{\infty} \gamma^{j} E_{t}\left(\lambda_{t+j}\right)
$$

Equation (20) implies that a positive $\phi_{t}$ represents the additional value of financial wealth for the firm in terms of its ability to reduce financing constraints. As long as $\phi_{t}>0$ then the gross return on money invested in the firm is higher than the gross market return $R$, and the firm does not distribute dividends $\left(d_{t}=0\right)$. Equations (17) and (18) are the first order conditions for variable capital and fixed capital respectively. In equation (18) the terms $\left(1+\phi_{t}\right) r$ and $\frac{\gamma}{R} E_{t}\left[\left(1+\gamma \phi_{t+2}\right) \pi_{t+1}^{k}\right]$ are the marginal cost and the marginal gross profits of fixed capital respectively. Capital $k_{t+1}$ is purchased at time $\mathrm{t}$, generates output during period $t+1$ but the corresponding profits become available at the beginning of period $t+2$, and therefore they are evaluated at their expected shadow value $\phi_{t+2} \cdot \mu_{t}$ is positive when the irreversibility constraint

\footnotetext{
${ }^{9}$ The value of $\pi_{t+1}^{l}$ is known at time $t$ because it does not depend on the term $\Lambda_{t+1}$.
} 
(2) is binding, and is equal to zero otherwise. The term $(1-\delta) \beta E_{t}\left(\mu_{t+1}\right)$ is the cost of future expected irreversibility constraints. In the next subsections we will describe the main qualitative features of the model. We will first analyze the solution without the financing constraint, then we will analyze the solution without the irreversibility constraint, and finally we will explain how the two constraints interact with each other.

\subsection{Solution with the irreversibility constraint only}

In this subsection we rule out current and future expected financing constraints by assuming that $w_{0}$, the initial wealth of the firm, is high enough so that the borrowing constraint (3) is never binding. This means that $\lambda_{t}=0$ for any $t$, and the first order conditions (16), (17) and (18) can be simplified as follows:

$$
\begin{gathered}
\phi_{t}=0 \\
\pi_{t+1}^{l}-r=0 \\
\frac{\gamma}{R} E_{t}\left(\pi_{t+2}^{k}\right)-r=\gamma\left(1-\delta_{k}\right) E_{t}\left(\mu_{t+1}\right)-R \mu_{t}
\end{gathered}
$$

Equations (2), (22) and (23) jointly determine $\mu_{t}, l_{t}$ and $k_{t+1}$. They describe the solution to a version of a well known irreversible investment problem (e.g. see Bertola and Caballero, 1994). Since we allow for a multifactor production technology the consequence is that $l_{t}$, the reversible factor, is more volatile than $k_{t}$, the irreversible factor, both after a positive and a negative shock. This follows from the comparison of equations (22) and (23). Equation (22) implies that variable capital always reacts to both positive and negative productivity shocks. Constraint (2) instead implies that, after a negative productivity shock at time $t, k_{t+1}$ cannot be reduced below $\left(1-\delta_{k}\right) k_{t}$, and as a consequence $\frac{\gamma}{R} E_{t}\left(\pi_{t+2}^{k}\right)$ decreases and is compensated by an increase in $\mu_{t}$ on the right hand side of equation (23). Instead after a positive productivity shock $\mu_{t}=0$ but $E_{t}\left(\mu_{t+1}\right)>0$ because constraint (2) can be binding at time $t+1$ conditional on a future negative shock. The positive value of $E_{t}\left(\mu_{t+1}\right)$ in equation (23) is compensated by a reduction in $k_{t+1}$ that increases $\frac{\gamma}{R} E_{t}\left(\pi_{t+2}^{k}\right)$.

\subsection{Solution with the financing constraint only}

In this section we rule out current and future expected irreversibility constraints by assuming that both variable capital and fixed capital are reversible, and the irreversibility constraint (2) no longer applies. Substituting $\mu_{t}=E_{t}\left(\mu_{t+1}\right)=0$ in (18) we obtain the following:

$$
\frac{\gamma}{R} E_{t}\left[\left(1+\gamma \phi_{t+2}\right) \pi_{t+2}^{k}\right]-\left(1+\phi_{t}\right) r=R \lambda_{t}-\gamma \tau_{k} E_{t}\left(\lambda_{t+1}\right)
$$

In this case equations (16), (17), (19) and (24) jointly determine $\phi_{t}, \lambda_{t}, l_{t}$ and $k_{t+1}$. If the firm does not have enough resources to invest optimally, then constraint (19) is binding with equality and both $\lambda_{t}$ and $\phi_{t}$ are positive. Equations (17) and (24) imply that a positive $\lambda_{t}$ increases both $\pi_{t+1}^{l}$ 
and $\pi_{t+2}^{k}$, and this reduces both $l_{t}$ and $k_{t+1}$. Suppose instead that the constraint (19) is not binding, but there is a positive probability to face future financing constraints. In this case $\lambda_{t}=0$ but $E_{t}\left(\lambda_{t+1}\right)$ and $\phi_{t}$ are positive. Equation (17) simplifies to equation (22), because future expected financing constraints do not directly affect $l_{t}$, the variable capital investment decisions. Regarding fixed capital, equation (24) implies that financing constraints expected at time $t+1$ have two counteracting effects on $k_{t+1}$. First, higher expected financing constraints increase $\gamma \tau_{k} E_{t}\left(\lambda_{t+1}\right)$, the expected collateral value of fixed capital in period $t+1$. This reduces $\frac{\gamma}{R} E_{t}\left[\left(1+\gamma \phi_{t+2}\right) \pi_{t+2}^{k}\right]$, the required gross return on capital, and increases $k_{t+1}$. Second, equation (17) implies that $E_{t}\left(l_{t+1}\right)$ decreases in $E_{t}\left(\lambda_{t+1}\right)$. This means that the more the firm is expected to be financially constrained in the next period, the lower is the expected level of variable capital investment $l_{t+1}$. Since $k_{t+1}$ and $l_{t+1}$ are complementary, it follows that the lower is $E_{t}\left(l_{t+1}\right)$, the lower is the expected profitability of fixed capital, and the lower is $k_{t+1}$. Simulation results show that this negative effect always dominates on the positive effect of the term $\gamma \tau_{k} E_{t}\left(\lambda_{t+1}\right)$. The implication is that two firms with identical technology and identical profitability, and both currently not financially constrained, may choose very different fixed capital investment levels depending on their level of wealth, because the latter affects future expected financing constraints. In section 4 we will show that this "precautionary" effect on investment is quantitatively important, and reduces the volatility of fixed capital in a way that is similar to the effect of convex adjustment costs.

\subsection{Solution with the financing and the irreversibility constraints}

We now consider the solution of the problem with both constraints. Instead of describing in detail such solution, we focus only on the most interesting feature, namely the fact that the irreversibility and the financing constraint interact and reinforce each other. Not only do financing constraints increase the cost of future irreversibility constraints, but also the irreversibility of fixed capital amplifies the effects of financing constraints on variable capital investment. In order to see this we evaluate equation (19) for $d_{t}=0$ and $k_{t+1}=(1-\delta) k_{t}$. This allows us to define an upper limit on new investment in variable capital:

$$
\left(1-\frac{\tau_{l}}{R}\right) l_{t} \leq w_{t}-\left[\left(1-\delta_{k}\right)-\frac{\tau_{k}}{R}\right] k_{t}
$$

The left hand side of equation (25) is the downpayment necessary to buy the variable capital $l_{t}$. $\left[\left(1-\delta_{k}\right)-\frac{\tau_{k}}{R}\right] k_{t}$ is the minimum financing needed to sustain the current level of fixed capital. Suppose now that the firm is hit by a persistent and negative productivity shock, so that both the financing and the irreversibility constraints are binding at times $t$ and $t+1$. By evaluating equation (25) with equality both at times $t$ and $t+1$ it follows that:

$$
\Delta l_{t+1}=\frac{R}{R-\tau_{l}}\left\{\Delta w_{t+1}+\delta_{k}\left[\left(1-\delta_{k}\right)-\frac{\tau_{k}}{R}\right] k_{t}\right\}
$$

Because $\delta_{k}$, the quarterly depreciation rate of fixed capital, is typically very small, equation (26) implies that the reduction in wealth caused by the negative shock $\left(\Delta w_{t+1}<0\right)$ is mainly absorbed by a negative change in variable capital $\left(\Delta l_{t+1}<0\right)$. This reduces the ratio $\frac{l_{t+1}}{k_{t+1}}$ below the optimal level. The unbalanced use of the factors of production reduces the productivity of fixed capital 
and the firm's output. This means that if a similar negative shock also hits the firm in period $t+2$ it will cause a bigger reduction in $w_{t+2}$ and $l_{t+2}$, and will further reduce the productivity of fixed capital and output, and so on.

We now illustrate the opposite amplification effect: future expected financing constraints increase the expected cost of a binding irreversibility constraint and reduce the incentive to invest in fixed capital. First we notice that, when both constraints are binding, $\mu_{t}$ is determined by equation (18). By substituting recursively we obtain:

$$
\mu_{t}=\frac{1}{R} \sum\left[\frac{\gamma\left(1-\delta_{k}\right)}{R}\right]^{j} E_{t}\left[\left(1+\phi_{t+j}\right) r-\frac{\gamma}{R}\left(1+\gamma \phi_{t+2+j}\right) \pi_{t+1+j}^{k}+R \lambda_{t+j}-\gamma \tau_{k} \lambda_{t+1+j}\right]
$$

In order to interpret equation (27) it is useful to evaluate it for the case of no financing constraints $\left(\lambda_{t}=\phi_{t}=0\right.$ for any $\left.t\right)$ :

$$
\mu_{t}=\frac{1}{R} \sum\left[\frac{\gamma\left(1-\delta_{k}\right)}{R}\right]^{j}\left[r-\frac{\gamma}{R} E_{t}\left[\pi_{t+1+j}^{k}\right]\right]
$$

The term $r-\frac{\gamma}{R} E_{t}\left[\pi_{t+1+j}^{k}\right]$ is positive if the irreversibility constraint is binding in period $t+j$. Therefore equation (28) shows that $\mu_{t}$ is the expected discounted sum of the marginal loss in revenues caused by the fact that the stock of fixed capital is inefficiently high when the irreversibility constraint is binding. Now compare equation (28) with equation (27). In the latter case, where the firm also faces financing imperfections, $\mu_{t}$ increases in $E_{t}\left(R \lambda_{t+j}-\gamma \tau_{k} \lambda_{t+1+j}\right)$. This term is positive, and represents the net cost of future expected financing constraints. The intuition is that the lower return on capital caused by the irreversibility constraint is going to be a bigger problem when the firm is financially constrained, and must rely on internal funds to finance investment. Therefore financing constraints increase the cost of irreversibility $\mu_{t}$. But this implies that they also increase the value of $E_{t}\left(\mu_{t+1}\right)$ when the irreversibility constraint is not currently binding, and so they make the firm more cautious about investing in fixed capital.

\section{Numerical Solution and simulations}

\subsection{The solution of the investment problem}

We solve the intertemporal maximization problem using a numerical method (see appendix B for details). Adding the subscript $i$ to indicate the generic $i-t h$ firm, the solution consists of the optimal policy functions $k_{i, t+1}\left(w_{i, t}, \theta_{i, t}, k_{i, t}\right)$ and $l_{i, t}\left(w_{i, t}, \theta_{i, t}, k_{i, t}\right)$, the associated Lagrange multipliers $\lambda_{i, t}\left(w_{i, t}, \theta_{i, t}, k_{i, t}\right), \mu_{i, t}\left(w_{i, t}, \theta_{i, t}, k_{i, t}\right)$ and $\phi_{i, t}\left(w_{i, t}, \theta_{i, t}, k_{i, t}\right)$, the value function $V_{i, t}^{\text {stay }}\left(w_{i, t}, \theta_{i, t}, k_{i, t}\right)$ and the liquidation rule $S_{t}\left(w_{i, t}, \theta_{i, t}, k_{i, t}\right) . \theta_{i, t}$ is defined as follows:

$$
\theta_{i, t}=\theta_{i, t}^{f} \varepsilon_{t}
$$

$\theta_{i, t}^{f}$ is the idiosyncratic productivity shock, and $\varepsilon_{t}$ is the industry-wide shock common to all firms. $\varepsilon_{t}$ is introduced in order to study the implications of the model for the dynamics of investment at the industry level. The model is otherwise partial equilibrium, with constant interest rate and 
constant relative prices normalized to 1 . Both $\theta_{i, t}^{f}$ and $\varepsilon_{t}$ are first order autoregressive stochastic processes:

$$
\begin{aligned}
\theta_{i, t}^{f} & =\rho_{\theta} \theta_{i, t-1}^{f}+\zeta_{i, t}^{\theta} \\
\zeta_{i, t}^{f} & \sim i i d N\left(\bar{\theta}, \sigma_{\theta}^{2}\right) \\
\varepsilon_{t} & =\rho_{\varepsilon} \varepsilon_{t-1}+\zeta_{t}^{\varepsilon} \\
\zeta_{t}^{\varepsilon} & \sim i i d N\left(0, \sigma_{\varepsilon}^{2}\right)
\end{aligned}
$$

In all the following simulations $\theta_{i, t}^{f}$ and $\varepsilon_{t}$ are discretised respectively as two states and eight states symmetric Markov processes:

$$
\begin{gathered}
\theta_{i, t}^{f}\left\{\theta_{L}, \theta_{H}\right\} \text { where } \theta_{L}<\theta_{H} \\
\varepsilon_{i, t}\left\{\varepsilon_{1}, \varepsilon_{2}, \ldots, \varepsilon_{8}\right\} \text { where } \varepsilon_{1}<\varepsilon_{2}<\ldots<\varepsilon_{8}
\end{gathered}
$$

The calibrated parameters are illustrated in table 4. We calibrate the model to match the long run averages of output and capital stock for the "Fabricated Metals Sector" in the US from 1962 to 1995 (source: NBER-CES manufacturing industry database, SIC code 34). Therefore the ability of the model to explain the cyclical fluctuations of investment will be measured by comparing the statistics from the simulated industry with the corresponding empirical data for the SIC 34 sector. This sector has been chosen as a generic representative one, but the theoretical model can be applied to any other sector where productive units use a combination of reversible and irreversible factors of production and can be subject to borrowing constraints. In fact in section 2 we showed that the stylized facts that this model aims at explaining are common to the whole of the US manufacturing sector as well as to almost all the 2 digits durable goods manufacturing sectors. The main advantage of using this sector, rather than the whole manufacturing industry, is that it has an high density of small firms. The SIC 34 sector is populated by many firms, 36429 according to the statistics for year 1992, the majority of which were small firms: $40.8 \%$ of the total payroll was generated from firms with less than 50 employees. Therefore it is reasonable to assume that a large share of these firms is affected by financing imperfections, like the firms in the simulated industry.

In calibrating the model the set of technological parameters $\alpha, \beta, \delta_{l}, \bar{\theta}, \rho_{\varepsilon}$ and $\sigma_{\varepsilon}$ are chosen to match the aggregate statistics about the SIC 34 sector. $\delta_{l}$ is set in order to match the average life of materials, with the following procedure: in the model $\left(1-\delta_{l}\right) l_{t}$ is the residual value of variable capital at the end of period $t$, after production takes place. Therefore we interpret $\left(1-\delta_{l}\right) l_{t}$ as the stock of input inventories, and the gross investment in variable capital can be interpreted as deliveries:

$$
\text { deliveries }_{t}=l_{t}-\left(1-\delta_{l}\right) l_{t-1}
$$

Total variable capital available for production in period $t$ is $l_{t}$, and $\delta_{l} l_{t}$ can be interpreted as the usage of materials in period $t$. Therefore $\delta_{l}$ must satisfy the following equation:

$$
\frac{\left(1-\delta_{l}\right) l_{t}}{\delta_{l} l_{t}}=\frac{\text { input inventories at the end of year } t}{\text { usage of materials in year } t}
$$


Solving for $\delta_{l}$ we obtain:

$$
\delta_{l}=\frac{1}{\frac{\text { input inventories at the end of year } t}{\text { usage of materials in year } t}+1}
$$

In the empirical data the ratio $\frac{\text { input inventories at the end of year } t}{\text { usage of materials in year } t}$ is approximately equal to one during the sample period. Thus $\delta_{l}$ is calibrated to be equal to $0.5 . \bar{\theta}$ is calibrated to match the average size of the firm. The elasticities $\alpha$ and $\beta$ match a chosen level of return to scale of 0.97 , which is consistent with empirical micro studies (Burnside, 1996), and the average ratio of fixed over variable capital. $\rho_{\varepsilon}$ and $\sigma_{\varepsilon}$ are chosen in order to match the volatility and autocorrelation of aggregate output for the detrended series of the SIC 34 sector.

The parameters $F, w_{0}$ and $\gamma$ affect the distribution and the turnover of firms in the simulated industry. They are jointly set to match the following statistics: i) the average fraction of firms that report negative net income in the US. Since this information is not available for the SIC 34 sector, we calculate it from a sample of more than 1300 US industrial companies drawn from the Worldscope Database and analyzed in Caggese (2006). ii) The turnover rate. In the model a firm that exits production is a firm that liquidates all its assets and is replaced by a newborn firm. Therefore this turnover can be interpreted as either firms destruction or as property change (the new firm acquires the assets of the liquidating firm). The annual average plant destruction rate in the SIC 34 sector has been $6.4 \%$ for the $1995-2000$ period. ${ }^{10}$ The rate of ownership change for the plants in the manufacturing sector can be inferred from "The Manufacturing Plant Ownership Change Database" (Nguyen, 1998). By dividing the number of ownership changes with the total number of plants surveyed, we calculate an annual rate of approximately $7.5 \%$. In the model this corresponds to a quarterly turnover rate of $3.67 \% .{ }^{11} \mathrm{iii}$ ) The size distribution of firms.

The parameters $\delta_{k}, \sigma_{\theta}$ and $\rho_{\theta}$ are calibrated to jointly match the average, the standard deviation and the autocorrelation of the investment rate in fixed capital. Since this information is not available for the SIC 34 sector, we match the values for the Compustat sample provided by Gomes (2001). Table 4 shows that the matching of the volatility and the autocorrelation of firm level investment is not perfect. One reason is that the mapping between the parameters and the moments matched is very nonlinear, and the volatility and persistency of the idiosyncratic shock affects contemporaneously many of the other moments, both at the firm and at the industry level. In particular it is difficult to match the autocorrelation coefficient of the fixed capital investment rate because of the absence of convex adjustment costs in the model. Despite this, the model with both constraints is still able to generate a positive autocorrelation of the fixed capital investment rate, because current and future expected financing constraints dampen the reaction of fixed capital to the productivity shocks, as illustrated in section 3.2 and in figure 1.

Regarding the financial parameters we set $r$, the quarterly real interest rate, equal to $1 \%$. Moreover we assume that the lenders cannot enforce the liquidation of variable capital to repay

\footnotetext{
${ }^{10}$ Both the exit rate statistics and the ownership change statistics actually refer to plants rather than to firms. But most of the firms in the SIC34 sector are small single plant firms, and therefore these statistics are a good approximation of their rate of turnover.

${ }^{11}$ This value is calculated by considering that the annual destruction rate and the property change rate are calculated on firms existing at the beginning of the year, and by assuming that the destruction probability is independent from the property change probability. Since we set $\gamma=0.965$, the exit rate of $3.75 \%$ in the simulated industry corresponds to $3.35 \%$ quarterly rate of exogenous liquidations and $0.4 \%$ of voluntary liquidations.
} 
the debt. Therefore $\tau_{l}$, the fraction of variable capital that can be used as collateral, is set equal to zero while $\tau_{k}$ matches the debt/assets ratio observed on average in the US corporate sector. This choice of allocating all the collateral capacity to the fixed capital is not necessarily consistent with the empirical evidence. However the results of the model are not sensitive to different assumptions regarding $\tau_{k}$ and $\tau_{l}$, as long as a significant fraction of firms is financially constrained in equilibrium. The last two columns of table 4 report the empirical moments matched in the calibration and the corresponding moments in the simulated industry with both constraints.

In the next sections we compare the simulations of the industry with the financing and irreversibility constraints with three alternative industries, one with only the financing constraint, one with only the irreversibility constraint, and one with no constraints. The benchmark parameters for all the industries are illustrated in table $4 .{ }^{12}$

Figures $1(\mathrm{I})$ and $1(\mathrm{II})$ show the value of the multipliers $\lambda_{t}\left(w_{t}, \theta_{t}, k_{t}\right)$ and $\phi_{t}\left(w_{t}, \theta_{t}, k_{t}\right)$ and the policy functions $l_{t}\left(w_{t}, \theta_{t}, k_{t}\right)$ and $k_{t+1}\left(w_{t}, \theta_{t}, k_{t}\right)$ in the space of $w_{t} / k^{a v g}$ and for selected values of $k_{t}$ and $\theta_{t} . k^{a v g}$ is the average optimal fixed capital for an unconstrained firm. $\theta_{t}$ is chosen so that figures 1 (I) and 1 (II) represent the investment decision of a firm with a negative idiosyncratic productivity shock $\left(\theta^{f}=\theta_{L}\right.$ and $\left.\varepsilon=\varepsilon_{7}\right)$. Figure 1 (II) illustrates the policy function of a firm that is only subject to the financing constraint, and hence is free to adjust fixed capital, while figure 1(I) illustrates the policy functions of a firm which is also subject to the irreversibility constraint. For both figures $k_{t}$ is chosen at an intermediate level so that, in the case of figure $1(\mathrm{I})$, the irreversibility constraint is not binding unless wealth is very low. The most interesting comparison is for values of wealth lower than $W^{*}$, when the financing constraint is binding and $\lambda_{t}$ is positive. In this case equation (19) holds with equality and $d_{t}=0$. Therefore a decrease in $w_{t}$ is compensated by a one to one decrease in $\left(1-\frac{\tau_{l}}{R}\right) l_{t}+k_{t+1}$. In the case of figure 1 (II), the drop in wealth is mostly absorbed by a drop in fixed capital. This is because the financing constraint is binding and hence the value of internally generated money is higher than the market price of it. $\phi_{t}$ (the "fi" line), the extra return of the funds invested in the firm, can be as high as $7 \%$ for very low levels of financial wealth. This means that it is very profitable to generate more output today, and the firm prefers to use its limited financial resources to invest in variable capital, which is immediately productive, and to reduce the investment in fixed capital.

In figure $1(\mathrm{I})$ both constraints are binding for levels of wealth below $W^{* *}$. In this case a drop in financial wealth must be absorbed by a drop in variable capital. Lower variable capital means that the firm produces less output today, generates less cash flow, and is expected to face even worse financial conditions in the future. The magnitude of this amplification effect is summarized by the fact that when $w_{t}$ is very low, $\lambda_{t}$ is up to ten times higher in figure 1(I) than in figure 1(II). The consequence is that $\phi_{t}$ can be as high as $58 \%$ in figure $1(\mathrm{II})$. This extreme value of $\phi_{t}$

\footnotetext{
${ }^{12}$ The main difference between the parameter sets of each industry is the difference in the volatility and persistency of the productivity shock. In the industry with only the irreversibility constraint it is necessary a very high persistency of the idiosyncratic shock to generate some autocorrelation in the fixed capital investment rate. $\rho_{\theta}$ is equal to 0.98 against $\rho_{\theta}=0.7$ in the industry with both constraints. In the industries with only the financing constraint and with no constraints it is not possible to match the autocorrelation of the fixed capital investment rate, no matter how close to $1 \rho_{\theta}$ is. Therefore we choose to set $\rho_{\theta}=0.7$ in the industry with only the financing constraint (the same as for the industry with both constraints). and $\rho_{\theta}=0.98$ for the industry with no constraints (the same as for the industry with only the irreversibility constraint).
} 
has a very low probability to happen in equilibrium, while values of $\phi_{t}$ between $10 \%$ and $15 \%$ are more frequent among the simulated firms with both constraints binding. Such values imply that the firms would be willing to pay between $44 \%$ and $64 \%$ annual interest rate to obtain additional finance. This may still seem an unrealistically high value, but actually the annualized interest rate that firms implicitly pay on trade credit is often found to be above $40 \%$ ( $\mathrm{Ng}$ et $\mathrm{Al}, 1999)$.

One interesting feature of the policy functions, present in both figures 1 (I) and 1(II), is the fact that fixed capital is sensitive to financial wealth when the financing constraint is not currently binding. As we mentioned in the previous section, this happens because fixed capital investment is negatively affected by future expected financing constraints. This "precautionary saving" effect is measured in figure $1(\mathrm{I})$ as the difference between $k_{t+1}^{u}$ and $k_{t+1}^{*}$. The first value, $k_{t+1}^{u}$, is the optimal fixed capital when $w_{t}$ is high enough so that the firm is not currently financially constrained. The second value, $k_{t+1}^{*}$, is the optimal fixed capital when $w_{t}$ is so high that the firm also does not expect to be financially constrained in the future. This precautionary reduction in fixed capital is especially large when the current stock of fixed capital $k_{t}$ is small. In this case $k_{t+1}^{u}$ can be up to $30 \%$ smaller than $k_{t+1}^{*}$.

\subsection{Dynamics of aggregate output and investment}

In this section we will use the solution of the model to simulate the investment and production path of many heterogeneous firms. We will show that the combination of the irreversibility and the financing constraint generates cyclical fluctuations of investment and output consistent with the empirical evidence illustrated in tables 1-3. In the simulated industry all firms are identical ex ante, but each of them is subject to a different realization of the idiosyncratic productivity shock $\theta_{i, t}^{f}$, which is uncorrelated across firms and serially correlated for each firm. The distribution of $\left\{w_{i, t}, k_{i, t}\right\}$ across firms depends on the set of exogenous parameters, on the initial distribution of

$\left\{w_{i, 0}, k_{i, 0}\right\}$ and on the history of aggregate shocks $\left\{\varepsilon_{j}\right\}_{j=0}^{t}$. In this section we compare the empirical data from the SIC 34 Sector with the data of several artificial industries. For each industry we simulate 50000 firms for 10000 periods. In each period a fraction $1-\gamma$ of firms is liquidated. We assume that an identical number of new firms enters production, so that the total number remains constant. Each newborn firm draws the initial value of $\theta^{f}$ from a uniform distribution, has an endowment of $w_{0}$ and a fixed capital level of $k_{0} . w_{0}$ is a key parameter to determine the aggregate distribution of wealth and the intensity of financing constraints. If $w_{0}$ is too small then no firm ever manages to expand enough to become unconstrained, and all firm are liquidated after few periods of life. If $w_{0}$ is too large then all firms can expand to the level at which they are never financially constrained. In the industry with both constraints $w_{0}$ is calibrated to be $33 \%$ of the average fixed capital of unconstrained firms. It is possible to show that for this value of $w_{0}$ a stochastic steady state exists such that a fraction of firms is on average financially constrained, and among those a significant fraction is contemporaneously financially and irreversibility constrained. Regarding $k_{0}$, we assume that the initial level of fixed capital of a firm that enters production at time $t$ is ex ante optimal, conditional on the information set at time $t-1$.

Tables 5-7 compare output and investment dynamics of the firms in the SIC 34 sector (first 
column) with the dynamics of the firms in four different artificial industries. These are simulated using the parameters shown in table 4, and correspond to the four versions of the model described in the previous section: without any constraint, with one of the two constraints only, and with both constraints. For the empirical data we compute fixed capital considering only the stock of equipment. This is because land and buildings are more likely to be subject to other type of adjustment costs besides the irreversibility constraint, which is the only type of real constraint considered in the model. For the simulated data, since we do not model finished goods inventories, sales and output coincide. The objective of this simulation exercise is to verify the ability of the model to replicate the following empirical evidence: i) the relative volatility of deliveries with respect to fixed capital; ii) the procyclicality and asymmetric behaviour of deliveries.

The last column in table 5 reports the simulated statistics for the industry without the irreversibility and the financing constraint. In this case the fixed capital stock is approximately as volatile as sales are. Deliveries are more volatile than fixed capital because they are measured as the gross investment in variable capital (see equation 32). This is, by construction, more volatile than the stock of variable capital $l_{t}$, which in the frictionless case is as volatile as fixed capital $k_{t}$. The correlation between the deliveries/sales ratio and the level of sales is positive and much larger than zero. This is due to the time to build assumption about fixed capital. After a positive shock firms can immediately increase variable capital input, while investment in fixed capital takes one period to become productive. Therefore deliveries increase proportionally more than sales after a positive shock. This can be interpreted as an increase in capacity utilization of the existing fixed capital stock. The time to build assumption alone can account for the procyclicality of deliveries, but it cannot account for its asymmetry: the procyclicality of deliveries is symmetrical across expansion and contraction phases.

The next column illustrates the statistics for the industry with the irreversibility constraint only, and shows a reduction in the volatility of fixed capital relative to the volatility of deliveries and sales. This is because in every period the irreversibility constraint is binding for a fraction of firms. These firms cannot change fixed capital in response to a negative productivity shock. Despite the irreversibility constraint is on average binding for as much as $32 \%$ of the firms, the increase in the volatility of variable capital relative to fixed capital is small. This is because the two factors of production are complementary. Therefore after a negative shock if a firm is unable to reduce fixed capital it has also less incentive to reduce variable capital deliveries. This implies that the lower volatility of fixed capital also causes a lower volatility of deliveries.

Regarding the asymmetric behaviour of deliveries in the business cycle, deliveries are more procyclical during upturns than during downturns. Therefore the introduction of an element of asymmetry in the model, the irreversibility constraint, generates an asymmetry in deliveries that is opposite to the one observed in the empirical data. Also this finding is explained by the complementarity of the two factors of production. In the simulated industry a downturn begins with a negative aggregate productivity shock that reduces output. As long as the low productivity persists, aggregate fixed capital is gradually reduced towards the new optimal level. The fact that irreversibility is binding for some firms implies that aggregate fixed capital is inefficiently high, and hence also variable capital deliveries are higher than otherwise. The inefficiently large 
capital implies that output drops more than variable capital during a downturn, and hence the deliveries/sales ratio is less procyclical in this phase than during an upturn.

The next column shows the simulated data for an industry with the financing constraint only. The relative volatility of deliveries is higher than in the two previous industries. The reason is that in this industry on average $43 \%$ of the firms have a binding financing constraint. For these firms the level of variable capital is inefficiently low, and hence its marginal productivity is high, leading to an higher sensitivity of variable capital to the productivity shock. Interestingly, financing constraints reduce the volatility of fixed capital more than the irreversibility constraint. This is due to the dampening effect of future expected financing constraints on current fixed capital investment decisions. Regarding the cyclical behaviour of variable capital, also this simulated industry is not consistent with the asymmetry of deliveries over the business cycle. Financing constraints increase the procyclicality of deliveries during expansion phases, as it happened in the industry with only the irreversibility constraint.

The next column shows the results of the simulation of an industry with both the financing and the irreversibility constraint. In this industry the ratio of the volatility of deliveries with respect to the volatility of fixed capital increases substantially, and is closer to the one observed in the empirical data. Moreover table 6, on the second row, shows that in this industry the relative volatility of input inventories is almost identical to the one in the data. The ratio of the volatility of input inventories over fixed capital is 3.14 in the data and 3.36 in the industry with the financing and the irreversibility constraint. Surprisingly, no additional convex or concave adjustment cost is needed to generate this result. This is due to the interactions between the two constraints. As explained in section 3.3, on the one hand the financing constraint amplifies the cost of future expected irreversibility constraints and discourages fixed capital investment. On the other hand the irreversibility of fixed capital amplifies the effect of financing constraints on deliveries when both constraints are binding. One way to quantify this amplification effect is to notice that if we add the irreversibility constraint to the industry with no frictions, the ratio between the volatility of deliveries relative to the volatility of fixed capital increases only by $5 \%$. Instead, if we add the irreversibility constraint on top of the financing constraint, this ratio increases by $75 \%$.

More importantly, the model with both constraints is consistent with the asymmetric behaviour of deliveries in expansion and contraction phases. Deliveries are more volatile than sales during periods in which sales are below trend, as it happens in the empirical data. The intuition for this result is that in this industry at any point in time a fraction of firms has both constraints currently binding. These firms, during a downturn, are forced to reduce deliveries in response to the reduction in profits and wealth. This effect more than counterbalances the fact that the more wealthy firms in the sample only have the irreversibility constraint binding and hence do not reduce deliveries with the same intensity. Less intuitive is the reason why deliveries are not procyclical during upturns. In figure 1 and in section 4.1 we have shown that when both constraints are binding the shadow cost of money for the firm reaches very high levels. Therefore also the marginal productivity of variable capital is very high, and when a positive aggregate shock hits and positive profits are realized, a small increase in deliveries generates large increases in output, and hence deliveries increase less than output for these firms. The ability of the model to match 
the observed behaviour of deliveries is important, because the asymmetric behaviour of deliveries is empirically closely related to the asymmetric dynamics of input inventories, as shown in table 2. Table 6 reports the procyclicality of inventory investment for the empirical data and for the simulated industries. Since we interpret the stock of variable capital at the end of period t, $\left(1-\delta_{l}\right) l_{t}$, as input inventories, $\left(1-\delta_{l}\right)\left(l_{t}-l_{t-1}\right)$ can be interpreted as inventory investment. Also in this case the industry with both constraints is the only one that reproduces the asymmetry in inventory dynamics found in the empirical data. Our model therefore provides a theoretical justification of the stylized fact that input inventories are very procyclical especially during recessionary periods. Furthermore, it is consistent with the finding of Gertler and Gilchrist (1994) and Bernanke, Gertler and Gilchrist (1996) who observe that at the beginning of a recession inventories decline much more in small rather than in large firms. Tables 6 shows that the asymmetric behaviour of input inventories in the industry with both constraints is entirely driven by the smaller firms.

The asymmetric behaviour of deliveries in the industry with both constraints is also reflected in the elasticity of deliveries to sales. Table 7 shows the estimated elasticity of deliveries to sales conditional on the number of consecutive periods of decreasing and increasing sales. For the simulated data the elasticity of deliveries to sales is very large in the first period of both expansion and contraction phases because fixed capital does not initially adjust to the new productivity shock. Therefore the sensitivity of output to the shock is less strong than the sensitivity of variable capital. In order to abstract from this effect we compare, in the bottom part of table 7 , the ratio between the elasticity of deliveries to sales in contraction and expansion periods. In the industry with both constraints this ratio is higher in the second and third period with respect to the first period, as it is in the data, while it is generally lower in the other simulated industries.

\subsection{Sensitivity analysis}

We now present a sensitivity analysis of the main results obtained in table 5 . In figures 2 and 3 we analyze the effect of a gradual increase in $w_{0}$, and hence of a reduction in the intensity of financing constraints, on the simulated statistics. In the previous section we claimed that the interactions between the financing and the irreversibility constraint are necessary to generate the high volatility of deliveries relative to fixed capital and their asymmetric dynamics. Here we confirm the claim by showing that these features of the simulated industry gradually disappear when $w_{0}$ increases.

In figures 2 and 3 the ratio $w_{0} / k^{a v g}$ is reported on the $x$ axis. The smallest value on the $x$ axis corresponds to the value of $w_{0}$ chosen in the simulations in the previous section. In figure 2(I) we illustrate the relationship between $w_{0}$ and the fraction of firms with a binding constraint. As $w_{0}$ increases, the fraction of firms with a binding borrowing constraint decreases. The fraction of firms with both constraints binding is initially relatively large, but it rapidly decreases towards zero. Therefore only firms with low wealth may experience both constraints contemporaneously binding. On the contrary the fraction of firms with the irreversibility constraint binding increases with $w_{0}$. This is because the higher is wealth, the more firms accumulate fixed capital, and the more the irreversibility constraint is likely to bind conditional on a negative idiosyncratic shock. ${ }^{13}$

\footnotetext{
${ }^{13}$ The fraction of firms with a binding irreversibility constraint is as high as $75 \%$ when no firm is ever financially constrained. This value is higher than the $36 \%$ obtained from the simulations that use the calibrated parameters
} 
Figure 2(II) shows that the volatility of deliveries relative to the volatility of fixed capital is very high for levels of $w_{0} / k^{a v g}$ between 0.3 and 0.6 . This happens despite in the same range of values of $w_{0}$ the fraction of financially constrained firms drops from $39 \%$ to $20 \%$. The reason is that these firms become unconstrained but most of them still expect future financing problems. From our analysis in section 3.2 we know that future financing constraints increase the cost of future irreversibility constraints and dampen the volatility of fixed capital. Therefore the relative volatility of deliveries to fixed capital remains high for these firms. When $w_{0}$ further increases, the ratio of the volatility of deliveries and fixed capital decreases faster. This is because more firms become very wealthy and with low probability of facing future financing constraints. Finally, figure 3 analyzes the asymmetry in the procyclicality of deliveries as a function of $w_{0}$, and shows that such asymmetry gradually disappears as $w_{0}$ increases.

\subsection{Irreversibility and aggregate output volatility}

Veracierto (2002), in a general equilibrium real business cycle model with heterogeneous firms, shows that the presence of the irreversibility constraint at firm level has negligible effects on aggregate investment and output dynamics. In this section we show that the irreversibility of fixed capital strongly reduces the volatility of output of the simulated industry when financing constraints are also present. This particular finding is sensitive to the assumption that relative prices are constant in our simulated industries. But still it suggests that the irrelevance result obtained by Veracierto (2002) may change if financing constraints were to be introduced in a simulated general equilibrium economy.

In table 8 we show the results of four simulated industries. The first column replicates the statistics of the industry with both constraints, previously reported in table 5 . The second column illustrates the statistics of an industry that has the same parameters of the industry of the first column, but that is not subject to irreversibility constraints. The fourth column replicates the results of the industry with only the irreversibility constraints, previously reported in table 5 . Finally the fifth column uses the same parameters of the industry in the fourth columns, but once again it relaxes the irreversibility constraint. Therefore the comparison of columns one and two is an estimation of the partial equilibrium effect on aggregate output of eliminating the irreversibility constraint in an industry with financing imperfections. The comparison between columns four and five is the same exercise on an industry without financing imperfections. In the latter case output volatility increases by $17 \%$. Also the relative volatilities of fixed capital and deliveries do not change much when the irreversibility constraint is eliminated. The former case yields very different results. If we eliminate the irreversibility constraint from an industry with financing imperfections, then the volatility of fixed capital relative to output increases by $97 \%$. This huge increase is due to the fact that by eliminating the irreversibility constraint we also eliminate the interactions with the financing constraint. The consequence is that the volatility of

for the industry with only the irreversibility constraint (table 5 , column 4 ) because in figure 2 we use the calibrated parameters for the industry with both constraints, which imply an higher volatility of the idiosyncratic shock. For the same reason the ratio between the volatilities of deliveries and fixed capital in figure 2(II) decreases from a maximum of 3.4 to 1.9 , which is less than the difference, shown in table 5 , between the calibrated economies with both constraints and with the irreversibility constraint only. 
output increases by as much as $116 \%$.

\section{Conclusions}

In this paper we have illustrated a structural model of a profit maximizing firm subject to both borrowing constraints and irreversibility of fixed capital. The solution of the optimal investment problem shows that not only expected productivity but also current and future expected financing constraints affect investment decisions. Despite the firm being risk neutral, future expected financing constraints may reduce current investment in fixed capital. This "precautionary" reduction in investment may substantially affect aggregate investment dynamics in a way similar to the effect of convex adjustment costs.

More importantly, we have shown that the irreversibility and the financing constraint are complementary. Notably, the irreversibility of fixed capital amplifies the effects of the financing constraint on variable capital. By simulating an artificial industry with many heterogeneous firms we have shown that this amplification effect explains why aggregate investment in input inventories and deliveries of US durable manufacturing firms are very volatile (relative to capital) and procyclical, and why such procyclicality is highly asymmetrical, so that it disappears in periods in which aggregate output is above its trend. Our model is also consistent with the stylized fact that the procyclicality of aggregate inventories during downturns is driven by small firms.

Although we calibrate the model to match one specific US two digits durable manufacturing sector, we show that a similar behaviour of inventories and deliveries is present also in most other durable good sectors. More generally, the implications of the model could be useful in understanding firm dynamics in any productive sector that satisfies the following assumptions: i) both financing and irreversibility constraints are binding for a non negligible share of firms in equilibrium; ii) firms produce output using a combination of reversible and irreversible inputs.

\section{References}

[1] Abel, A.B. and J. Eberly, 1999, The Effects of Irreversibility and Uncertainty on Capital Accumulation, Journal of Monetary Economics 44, 339-377.

[2] Albuquerque, R. and H.A. Hopenhayn, 2004, Optimal Lending Contracts and Firm Dynamics, The Review of Economic Studies 71, 285-315.

[3] Bernanke, B., Gertler, M. and S. Gilchrist, 1996, "The Financial Accelerator and the Flight to Quality", The Review of Economics and Statistics, 78, 1-15.

[4] Bertola, G. and R. Caballero, 1994, Irreversibility and Aggregate Investment, Review of Economics Studies 61, 223-246.

[5] Besanko, D. and A.V. Thakor, 1986, Collateral and Rationing: Sorting Equilibria in Monopolistic and Competitive Credit Markets, International Economic Review 28, 671-689.

[6] Blinder, A.S. and L. Maccini, 1991, Taking Stock: A Critical Assessment of Recent Research on Inventories, Journal of Economic Perspectives 5, 73-96. 
[7] Burnside, C., 1996, Production Function Regressions, Returns to Scale, and Externalities, Journal of Monetary Economics 37, 177-201.

[8] Caballero, R.J., 1999, Aggregate Investment, in: J. B. Taylor and M. Woodford, eds., Handbook of Macroeconomics, Vol. 1 (Elsevier) 813-862.

[9] Caballero, R.J., Engel, E. and J. Haltiwanger, 1995, Plant-Level Adjustment and Aggregate Investment Dynamics, Brookings Papers on Economic Activity, 1-54.

[10] Caggese A., 2006, Testing Financing Constraints on Labour Demand and R\&D, Pompeu Fabra University working paper.

[11] Cooley, T., Marimon, R. and V. Quadrini, 2004, Aggregate Consequences of Limited Contract Enforceability, Journal of Political Economy 112, 817-847.

[12] Cooley, T. and V. Quadrini, 2001, Financial Markets and Firm Dynamics, American Economic Review 91, 1286-1310.

[13] Gertler, M. and S. Gilchrist, 1994, Monetary Policy, Business Cycle, and the Behaviour of Small Manufacturing Firms, Quarterly Journal of Economics 109, 309-340.

[14] Gomes, J., 2001, Financing Investment, American Economic Review 91, 1263-1285.

[15] Hart, O. and J.H. Moore, 1998, Default and Renegotiation: a Dynamic Model of Debt, Quarterly Journal of Economics 113, 1-41.

[16] Holt, R.W.P., 2003, Investment and Dividends Under Irreversibility and Financial Constraints, Journal of Economic Dynamics and Control 27, 467-502.

[17] Hornstein, A., 1998, Inventory Investment and the Business Cycle, Federal Reserve Bank of Richmond Economic Quarterly 84, 49-71.

[18] Hubbard, G.R., 1998, Capital-Market Imperfections and Investment, Journal of Economic Literature 36, 193-225.

[19] Humphreys, B. R., Maccini, L. J. and S. Schuh, 2001, Input and Output Inventories, Journal of Monetary Economics 47, 347-375.

[20] Jermann, U. and V. Quadrini 2006, Stock Market Boom and the Productivity Gains of the 1990s, Journal of Monetary Economics, forthcoming.

[21] Kiyotaki, N. and J. Moore, 1997, Credit Cycles, Journal of Political Economy 105, 211-48.

[22] Milde, H. and J.G. Riley, 1988, Signalling in Credit Markets, Quarterly Journal of Economics 103, 101-129.

[23] Ng, C.K., Smith J.K. and R.L.Smith, 1999, Evidence on the Determinants of Credit Terms Used in Interfirm Trade, Journal of Finance 54, 1109-1129.

[24] Nguyen, S., 1998, The Manufacturing Plant Ownership Change Database: Its Construction And Usefulness, Economic Studies 98-16, US Census.

[25] Ramey, V.A., 1989, Inventories as Factors of Production and Economic Fluctuations, American Economic Review, 79, 338-54. 
[26] Ramey, V. and K. West, 1999, Inventories, in: J. B. Taylor \& M. Woodford, eds.), Handbook of Macroeconomics, Vol. 1 (Elsevier) 863-923.

[27] Scaramozzino, P., 1997, Investment Irreversibility and Finance Constraints, Oxford Bulletin of Economics and Statistics 59, 89-108.

[28] Stiglitz, J. and A. Weiss, 1981, Credit Rationing in Markets with Imperfect Information, American Economic Review 71, 912-927.

[29] Veracierto, M., 2002, Plant-Level Irreversible Investment and Equilibrium Business Cycles, American Economic Review 92, 181-97.

\section{Appendix A: solution of the problem with endogenous exit:}

In section 3 of the paper we illustrated the first order conditions of the firm's problem for the simplified case in which endogenous exit does not happen in equilibrium. Here we illustrate the full solution of the problem. If we substitute recursively $V_{t+1}^{\text {stay }}\left(w_{t+1}, \theta_{t+1}, k_{t+1}\right)$ in equation (9) and we add constraints (2), (3) and (6) at times $t$ and $t+1$, with the associated Lagrangian multipliers $\mu, \lambda$ and $\phi$, we can represent the problem in the following way:

$$
\begin{gathered}
V_{t}^{\text {stay }}\left(w_{t}, \theta_{t}, k_{t}\right)=\left(1+\phi_{t}\right)\left(w_{t}+\frac{b_{t}}{R}-k_{t+1}-l_{t}\right)+\mu_{t}\left[k_{t+1}-\left(1-\delta_{k}\right) k_{t}\right]+\lambda_{t}\left[\tau_{k} k_{t}+\tau_{l} l_{t}-b_{t}\right]+ \\
+\frac{1}{R} E_{t}\left\{\left(1-\gamma S_{t+1}\right) w_{t+1}+\gamma S_{t+1}\left\{\left(1+\phi_{t+1}\right)\left(w_{t+1}+\frac{b_{t+1}}{R}-k_{t+2}-l_{t+1}\right)+\right.\right. \\
\left.\left.\quad+\mu_{t+1}\left[k_{t+2}-\left(1-\delta_{k}\right) k_{t+1}\right]+\lambda_{t+1}\left[\tau_{k} k_{t+1}+\tau_{l} l_{t+1}-R b_{t+1}\right]\right\}\right\}+ \\
+\frac{\gamma}{R^{2}} E_{t}\left\{S_{t+1}\left\{E_{t+1}\left[\gamma S_{t+2} V_{t+2}^{\text {stay }}\left(w_{t+2}, \theta_{t+2}, k_{t+2}\right)+\left(1-\gamma S_{t+2}\right) w_{t+2}\right]\right\}\right\}
\end{gathered}
$$

The first order conditions of the problem are the following:

$$
\begin{gathered}
1+\phi_{t}=R \lambda_{t}+E_{t}\left(1+\gamma S_{t+1} \phi_{t+1}\right)+\gamma E_{t}\left(\Gamma_{t+1}\right) \\
\frac{\partial y_{t}}{\partial l_{t}}=U L+\frac{R\left(R-\tau_{l}\right) \lambda_{t}}{E_{t}\left(1+\gamma S_{t+1} \phi_{t+1}+\gamma \Gamma_{t+1}\right)} \\
E_{t}\left(\frac{\partial y_{t+1}}{\partial l_{t+1}}\right)=\frac{R^{3} \lambda_{t}+R U K E_{t}\left(1+\gamma S_{t+1} \phi_{t+1}+\gamma \Gamma_{t+1}\right)-R^{2} \mu_{t}}{\gamma^{2} E_{t}\left(S_{t+1} \Psi_{t+1}\right)}+ \\
-\frac{\gamma R E_{t}\left\{S_{t+1}\left[\lambda_{t+1} \tau_{k}-\mu_{t+1}\left(1-\delta_{k}\right)\right]\right\}+\gamma R E_{t}\left[\Omega_{t+1}\right]+\gamma^{2} \operatorname{covar}_{t+1}}{\gamma^{2} E_{t}\left(S_{t+1} \Psi_{t+1}\right)}
\end{gathered}
$$

Where:

$$
\begin{gathered}
\Gamma_{t+1} \equiv \frac{\partial S_{t+1}}{\partial w_{t+1}}\left\{\frac{\gamma}{R}\left\{E_{t+1}\left[\left[V_{t+2}\left(w_{t+2}, \theta_{t+2}, k_{t+2}\right)\right]+\frac{(1-\gamma)}{\gamma} w_{t+2}\right]\right\}-w_{t+1}\right\} \\
\Omega_{t+1} \equiv \frac{\partial S_{t+1}}{\partial k_{t+1}}\left\{\frac{\gamma}{R}\left\{E_{t+1}\left[\left[V_{t+2}\left(w_{t+2}, \theta_{t+2}, k_{t+2}\right)\right]+\frac{(1-\gamma)}{\gamma} w_{t+2}\right]\right\}-w_{t+1}\right\} \\
\Psi_{t+1}=S_{t+1}\left[\frac{1}{\gamma}+E_{t+1}\left(S_{t+2} \phi_{t+2}\right)\right]
\end{gathered}
$$




$$
\operatorname{covar}_{t+1}=\operatorname{cov}\left(M P K_{t+1}, S_{t+1} \Psi_{t+1}\right)
$$

Equations (16), (17) and (18) are a special case of (36), (37) and (38) for $S_{t}=1$ for any $t$. The terms $\Gamma_{t+1}$ and $\Omega_{t+1}$ can be shown to be always equal to zero if inefficient liquidation never happens in equilibrium.

\section{Appendix B: numerical solution}

In order to obtain a numerical solution of the dynamic nonlinear system defined by equations (2), (36), (37), (38) and (19), plus the standard complementary slackness conditions on $\lambda_{t}, \mu_{t}$ and $\phi_{t}$, we discretise the state space as follows: $k_{t}$ and $w_{t}$ are both discretised in a 60 points grid, while $\theta_{t}$ is discretised in 16 elements, which correspond to the eight states of the aggregate shock and the two states of the idiosyncratic shock. The solution of the problem is simplified by the fact that, for all the set of parameters chosen in the paper, inefficient liquidation never happens in equilibrium, so that we can calculate the solution for the special case in which the terms $\Gamma_{t+1}$ and $\Omega_{t+1}$ are always equal to zero. In order to compute the solution, first we formulate an initial guess of the forward terms $E_{t}\left(S_{t+1} \phi_{t+1}\right), E_{t}\left(S_{t+1} \Psi_{t+1}\right), E_{t}\left(S_{t+1} \lambda_{t+1}\right), E_{t}\left(S_{t+1} \mu_{t+1}\right)$ and $\operatorname{covar}_{t+1}$. Second, we solve the static optimization problem conditional on this guess, for each discrete value of the state variables $w_{i, t}, k_{i, t}$ and $\theta_{i, t}$. Third, we update the guess of $E_{t}\left(S_{t+1} \phi_{t+1}\right)$, $E_{t}\left(S_{t+1} \Psi_{t+1}\right), E_{t}\left(S_{t+1} \lambda_{t+1}\right), E_{t}\left(S_{t+1} \mu_{t+1}\right)$ and $\operatorname{covar}_{t+1}$. We repeat these steps until the value function converges.

\section{Figures and Tables}

Figure 1: Policy functions conditional on $\theta^{f}=\theta_{L}, \varepsilon=\varepsilon_{7}$ and $k_{t}=87576$
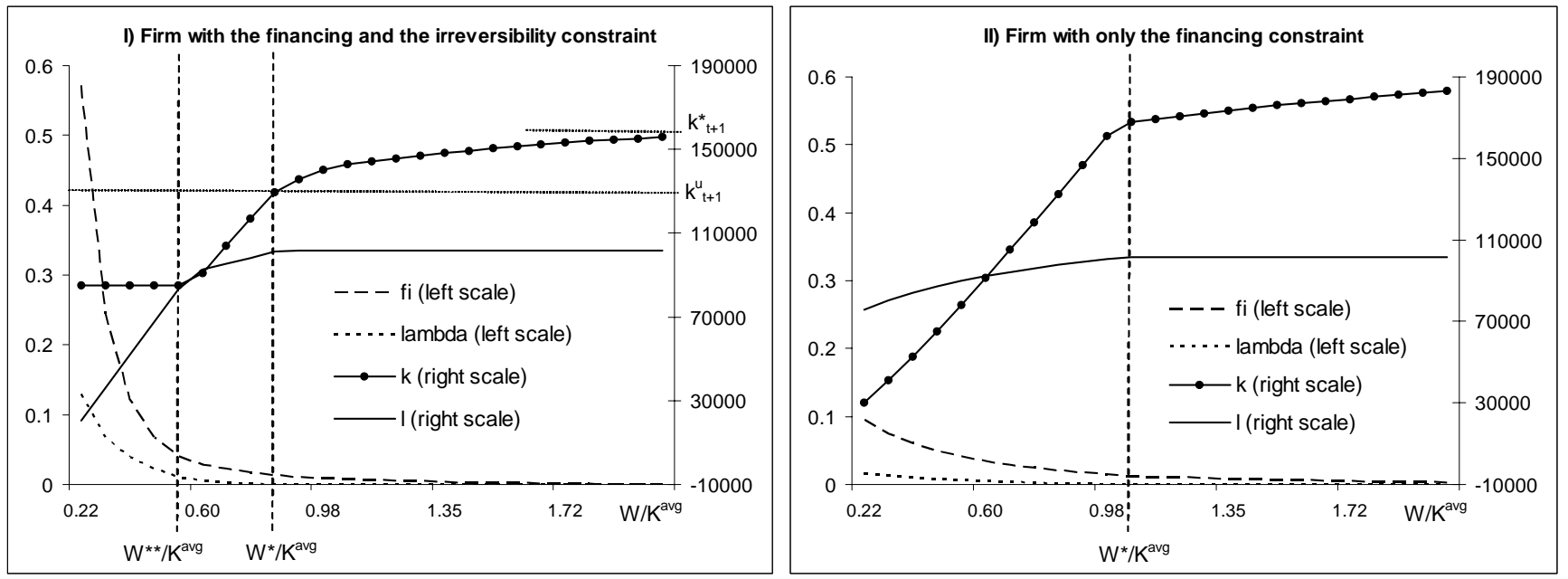
Figure 2: Financial wealth, fraction of constrained firms and volatility of investment (industry with both constraints)
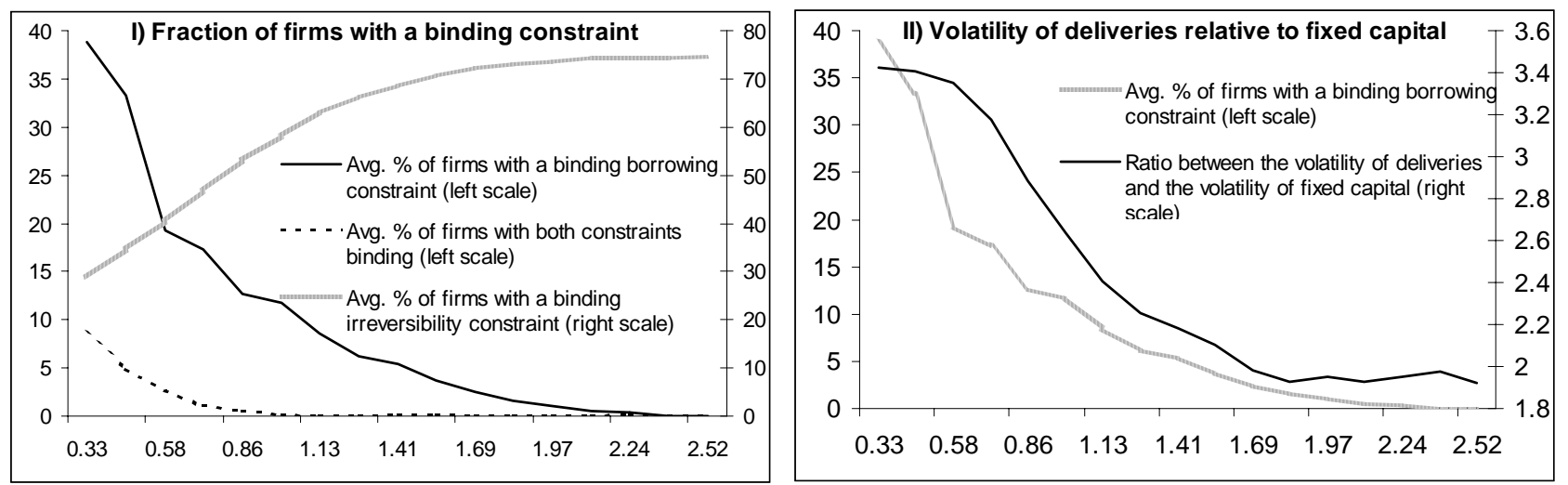

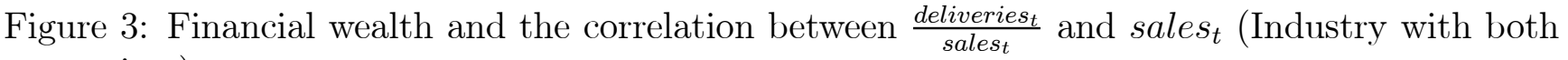
constraints)
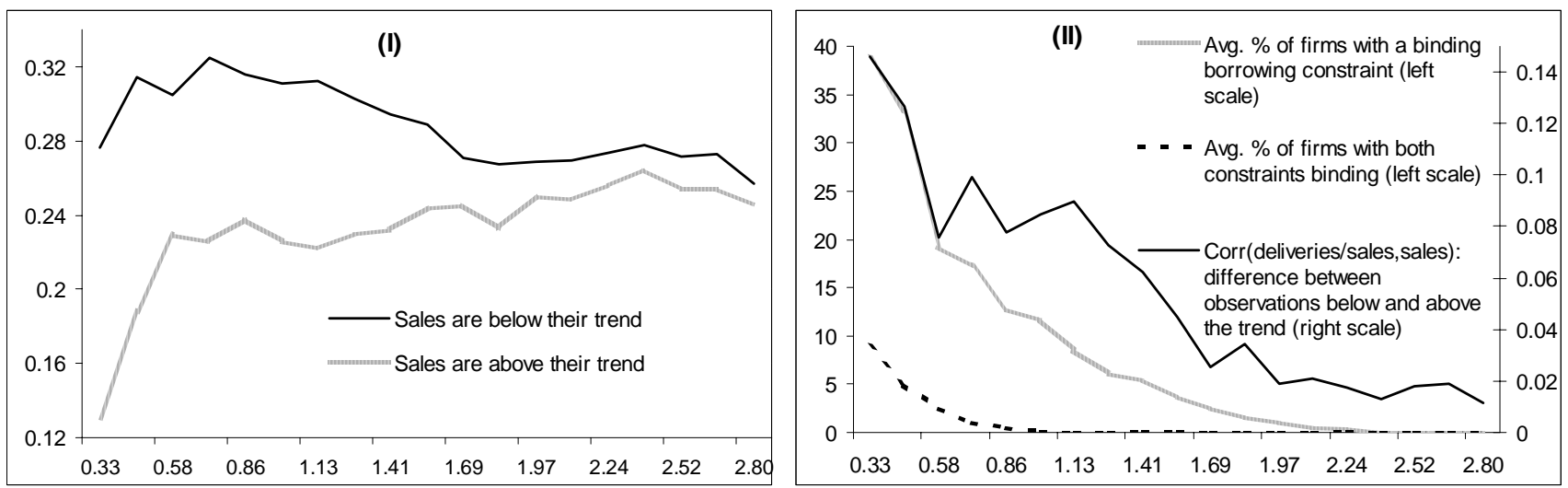
Table 1: Volatility and procyclicality of deliveries and inventories

\begin{tabular}{|c|c|c|c|c|c|c|c|}
\hline & \multicolumn{5}{|c|}{ Standard Deviations } & \multicolumn{2}{|c|}{ Correlations } \\
\hline Sector & Sales & Deliveries & $\begin{array}{l}\text { Material } \\
\text { inventories }\end{array}$ & $\begin{array}{l}\text { Work in } \\
\text { progress }\end{array}$ & $\begin{array}{l}\text { Final goods } \\
\text { inventories }\end{array}$ & $\left(\frac{\Delta i n v_{t}}{s_{t}}, s_{t}\right)$ & $\left(\frac{d e l_{t}}{s_{t}}, s_{t}\right)$ \\
\hline SIC 32 & 0.043 & 0.056 & 0.034 & 0.039 & 0.032 & $\begin{array}{c}0.038^{* *} \\
(0.009)\end{array}$ & $\begin{array}{c}0.006 \\
(0.065)\end{array}$ \\
\hline SIC 33 & 0.086 & 0.094 & 0.050 & 0.044 & 0.059 & $\begin{array}{c}0.038^{* *} \\
(0.012)\end{array}$ & $\begin{array}{c}0.068 \\
(0.023)\end{array}$ \\
\hline SIC 34 & 0.043 & 0.059 & 0.056 & 0.033 & 0.034 & $\begin{array}{c}0.076^{* *} \\
(0.026)\end{array}$ & $\begin{array}{c}0.180 * * \\
(0.060)\end{array}$ \\
\hline SIC 35 & 0.061 & 0.080 & 0.061 & 0.058 & 0.051 & $\begin{array}{c}0.078 * * \\
(0.021)\end{array}$ & $\begin{array}{c}0.162^{* *} \\
(0.053)\end{array}$ \\
\hline SIC 36 & 0.057 & 0.075 & 0.075 & 0.061 & 0.058 & $\begin{array}{c}0.118^{* *} \\
(0.019)\end{array}$ & $\begin{array}{c}0.155^{* *} \\
(0.059)\end{array}$ \\
\hline SIC 37 & 0.066 & 0.083 & 0.058 & 0.066 & 0.053 & $\begin{array}{c}0.040^{* *} \\
(0.016)\end{array}$ & $\begin{array}{c}0.191^{* *} \\
(0.035)\end{array}$ \\
\hline SIC 38 & 0.039 & 0.073 & 0.068 & 0.069 & 0.059 & $\begin{array}{c}0.027 \\
(0.031)\end{array}$ & $\begin{array}{c}0.312 \\
(0.099)^{* *}\end{array}$ \\
\hline
\end{tabular}

Quarterly data. Standard deviations are calculated on the trend deviations computed using the Hodrick Prescott filter (smoothing parameter $\lambda=1600$ ). Standard errors are in parenthesis. The sectors are the following: SIC 32: Stone, Clay, Glass Products. SIC 33: Primary Metals. SIC 34: Fabricated metal products. SIC 35: Industrial machinery. SIC 36: Electronic and other electric equipment. SIC 37: Transportation Equipment. SIC 38: Instruments and related products. ${ }^{* *}$ Significant at the $99 \%$ confidence level; ${ }^{*}$ significant at the $95 \%$ confidence level. 
Table 2: Asymmetry in the prociclicality of inventories and deliveries

\begin{tabular}{|c|c|c|c|c|c|c|c|c|}
\hline & \multirow{2}{*}{$\begin{array}{r}\operatorname{corr} \\
\text { Below } \\
\text { trend }\end{array}$} & \multicolumn{3}{|c|}{ 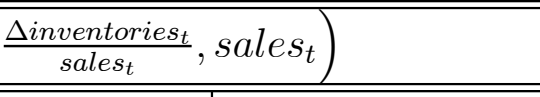 } & \multicolumn{2}{|r|}{ corr } & \multicolumn{2}{|c|}{$\begin{array}{l}\text { eliveries }_{t} \\
\text { salest }_{t}\end{array}$ sales $\left.s_{t}\right)$} \\
\hline & & $\begin{array}{r}\text { Above } \\
\text { trend }\end{array}$ & $\begin{array}{l}\text { Sales } \\
\text { down }\end{array}$ & $\begin{array}{l}\text { Sales } \\
\text { up }\end{array}$ & $\begin{array}{r}\text { Below } \\
\text { trend }\end{array}$ & $\begin{array}{l}\text { Above } \\
\text { trend }\end{array}$ & $\begin{array}{l}\text { Sales } \\
\text { down }\end{array}$ & $\begin{array}{l}\text { Sales } \\
\text { up }\end{array}$ \\
\hline $\begin{array}{c}\text { All } \\
\text { sectors }\end{array}$ & $\begin{array}{r}0.109^{* *} \\
(0.025)\end{array}$ & $\begin{array}{c}0.038 \\
(0.033)\end{array}$ & $\begin{array}{r}0.076^{* *} \\
(0.021)\end{array}$ & $\begin{array}{r}0.084^{* *} \\
(0.020)\end{array}$ & $\begin{array}{l}0.145^{* *} \\
(0.029)\end{array}$ & $\begin{array}{l}0.091^{*} \\
(0.039)\end{array}$ & $\begin{array}{l}0.083^{* *} \\
(0.024)\end{array}$ & $\begin{array}{l}0.096^{* *} \\
(0.024)\end{array}$ \\
\hline SIC 32 & $\begin{array}{l}0.037^{*} \\
(0.017)\end{array}$ & $\begin{array}{l}0.040^{*} \\
(0.020)\end{array}$ & $\begin{array}{c}0.041^{* *} \\
(0.013)\end{array}$ & $\begin{array}{c}0.036^{*} \\
(0.015)\end{array}$ & $\begin{array}{c}0.053^{* *} \\
(0.136)\end{array}$ & $\begin{array}{c}-0.029 \\
(0.114)\end{array}$ & $\begin{array}{c}-0.006 \\
(0.088)\end{array}$ & $\begin{array}{c}0.021^{*} \\
(0.099)\end{array}$ \\
\hline SIC 33 & $\begin{array}{c}0.070^{* *} \\
(0.023)\end{array}$ & $\begin{array}{c}0.006 \\
(0.023)\end{array}$ & $\begin{array}{c}0.037^{*} \\
(0.017)\end{array}$ & $\begin{array}{c}0.042^{*} \\
(0.019)\end{array}$ & $\begin{array}{l}0.108^{*} \\
(0.044)\end{array}$ & $\begin{array}{c}0.028 \\
(0.045)\end{array}$ & $\begin{array}{r}0.099^{* *} \\
(0.036)\end{array}$ & $\begin{array}{c}0.044 \\
(0.032)\end{array}$ \\
\hline SIC 34 & $\begin{array}{c}0.101^{* *} \\
(0.044)\end{array}$ & $\begin{array}{c}0.040 \\
(0.058)\end{array}$ & $\begin{array}{c}0.128^{* *} \\
(0.036)\end{array}$ & $\begin{array}{c}0.022 \\
(0.037)\end{array}$ & $\begin{array}{c}0.280^{* *} \\
(0.110)\end{array}$ & $\begin{array}{c}0.030 \\
(0.130)\end{array}$ & $\begin{array}{c}0.230^{*} \\
(0.090)\end{array}$ & $\begin{array}{c}0.120 \\
(0.090)\end{array}$ \\
\hline SIC35 & $\begin{array}{c}0.174^{* *} \\
(0.042)\end{array}$ & $\begin{array}{c}-0.036 \\
(0.048)\end{array}$ & $\begin{array}{r}0.104^{* *} \\
(0.032)\end{array}$ & $\begin{array}{l}0.072^{*} \\
(0.029)\end{array}$ & $\begin{array}{r}0.411^{* *} \\
(0.103)\end{array}$ & $\begin{array}{c}-0.133 \\
(0.118)\end{array}$ & $\begin{array}{l}0.213^{* *} \\
(0.078)\end{array}$ & $\begin{array}{c}0.155^{*} \\
(0.074)\end{array}$ \\
\hline SIC36 & $\begin{array}{c}0.063 \\
(0.037)\end{array}$ & $\begin{array}{c}0.175^{* *} \\
(0.038)\end{array}$ & $\begin{array}{c}0.139^{* *} \\
(0.029)\end{array}$ & $\begin{array}{c}0.102^{* *} \\
(0.027)\end{array}$ & $\begin{array}{c}0.003 \\
(0.112)\end{array}$ & $\begin{array}{r}0.317^{* *} \\
(0.117)\end{array}$ & $\begin{array}{c}0.108 \\
(0.088)\end{array}$ & $\begin{array}{c}0.199 * \\
(0.081)\end{array}$ \\
\hline SIC37 & $\begin{array}{c}0.071^{* *} \\
(0.027)\end{array}$ & $\begin{array}{c}0.002 \\
(0.031)\end{array}$ & $\begin{array}{c}0.0486^{*} \\
(0.022)\end{array}$ & $\begin{array}{c}0.047^{*} \\
(0.026)\end{array}$ & $\begin{array}{c}0.239^{* *} \\
(0.057)\end{array}$ & $\begin{array}{c}0.129 \\
(0.067)\end{array}$ & $\begin{array}{c}0.186^{* *} \\
(0.046)\end{array}$ & $\begin{array}{c}0.225^{* *} \\
(0.055)\end{array}$ \\
\hline SIC38 & $\begin{array}{c}0.113^{*} \\
(0.052)\end{array}$ & $\begin{array}{c}-0.072 \\
(0.057) \\
\end{array}$ & $\begin{array}{c}0.089^{*} \\
(0.046)\end{array}$ & $\begin{array}{l}-0.007 \\
(0.043)\end{array}$ & $\begin{array}{c}0.569^{* *} \\
(0.168)\end{array}$ & $\begin{array}{c}0.017 \\
(0.185)\end{array}$ & $\begin{array}{c}0.533^{* *} \\
(0.146)\end{array}$ & $\begin{array}{c}0.169 \\
(0.138)\end{array}$ \\
\hline
\end{tabular}

Quarterly data. The series $\frac{\text { inventories }_{t}}{\text { salest }_{t}}, \frac{\text { deliveries }_{t}}{\text { salest }_{t}}$ and sales $_{t}$ are percentage deviations from their trend computed using the Hodrick-Prescott filter (smoothing parameter $\lambda=1600$ ). Standard errors are in parenthesis.

$* *$ significant at the $99 \%$ confidence level; *significant at the $95 \%$ confidence level. 
Table 3: Elasticity of deliveries to sales : $\frac{\Delta \text { deliveries }_{t}}{\Delta \text { sales }_{t}}$

\begin{tabular}{l|c|c|c|c|c|c}
\hline \hline & \multicolumn{3}{|c|}{ Contractions in Sales } & \multicolumn{3}{c}{ Expansions in Sales } \\
\hline \hline Total & 1st quarter & 2nd quarter & 3rd quarter & 1st quarter & 2nd quarter & 3rd quarter \\
Manufacturing & $1.23^{* *}$ & $1.27^{* *}$ & $1.20^{* *}$ & $0.93^{* *}$ & $1.21^{* *}$ & $1.17^{* *}$ \\
& $(0.15)$ & $(0.12)$ & $(0.37)$ & $(0.18)$ & $(0.19)$ & $(0.28)$ \\
SIC 32 & $0.70^{*}$ & $0.78^{*}$ & $0.99^{*}$ & $0.82^{* *}$ & $1.35^{* *}$ & 1.22 \\
& $(0.33)$ & $(0.41)$ & $(0.51)$ & $(0.31)$ & $(0.34)$ & $(0.72)$ \\
SIC 33 & $0.79^{* *}$ & $0.75^{* *}$ & $1.18^{* *}$ & $1.27^{* *}$ & $1.17^{* *}$ & $1.18^{* *}$ \\
& $(0.07)$ & $(0.11)$ & $(0.12)$ & $(0.09)$ & $(0.11)$ & $(0.17)$ \\
SIC 34 & $1.15^{* *}$ & $1.66^{* *}$ & $1.98^{*}$ & $1.14^{*}$ & $1.18^{* *}$ & $0.91^{* *}$ \\
& $(0.36)$ & $(0.29)$ & $(0.83)$ & $(0.49)$ & $(0.31)$ & $(0.31)$ \\
SIC 35 & $1.41^{* *}$ & $1.77^{* *}$ & $2.06^{* *}$ & $0.67^{*}$ & 0.53 & $1.00^{* *}$ \\
& $(0.24)$ & $(0.45)$ & $(0.29)$ & $(0.34)$ & $(0.38)$ & $(0.34)$ \\
& & & & & & \\
SIC 36 & $1.37^{* *}$ & $0.99^{* *}$ & $1.30^{* *}$ & 0.20 & $1.28^{* *}$ & $1.34^{* *}$ \\
& $(0.31)$ & $(0.34)$ & $(0.40)$ & $(0.46)$ & $(0.42)$ & $(0.34)$ \\
SIC 37 & $1.09^{* *}$ & $1.21^{* *}$ & $0.76^{* *}$ & $0.96^{* *}$ & $1.00^{* *}$ & 0.58 \\
& $(0.12)$ & $(0.08)$ & $(0.17)$ & $(0.07)$ & $(0.14)$ & $(0.48)$ \\
& & & & & & $1.79^{*}$ \\
& $1.19^{*}$ & $1.66^{*}$ & 1.77 & $1.98^{* *}$ & 0.59 & $(0.83)$ \\
\hline \hline
\end{tabular}

The estimated elasticities conditional on more than three consecutive periods of contraction or expansion in detrended real sales are not reported because too few observations do not allow us to estimate significant coefficients. Standard errors are in parenthesis. ${ }^{* *}$ significant at the $99 \%$ confidence level; *significant at the $95 \%$ confidence level. 
Table 4: Benchmark parameters

\begin{tabular}{|c|c|c|c|c|c|c|c|}
\hline & \multicolumn{4}{|c|}{ Calibrated parameters } & \multirow[b]{2}{*}{$\begin{array}{l}\text { Empirical } \\
\text { restriction }\end{array}$} & \multicolumn{2}{|c|}{ Matched moments } \\
\hline & $\mathrm{I}$ & II & III & IV & & $\begin{array}{l}\text { Empirical } \\
\text { data }\end{array}$ & $\begin{array}{l}\text { Industry with } \\
\text { both constraints }\end{array}$ \\
\hline$\alpha$ & .08 & .75 & .088 & .072 & $\overline{k_{t} / l_{t}}$ & $1.06^{3}$ & 1.02 \\
\hline$\beta$ & .89 & .895 & .882 & .898 & returns to scale & $0.97^{3}$ & 0.97 \\
\hline$\delta_{l}$ & .5 & .5 & .5 & .5 & $\frac{\text { usage of materials }}{\text { input inventories }}$ & $\approx 1^{3}$ & 1 \\
\hline$\rho^{a}$ & .9 & .9 & .95 & .9 & $\operatorname{corr}\left(y_{t}, y_{t+1}\right)$ & $0.77^{3}$ & 0.70 \\
\hline$\sigma^{a}$ & .0015 & .002 & .0075 & .0097 & st.dev. $\left(\right.$ sales $\left._{t}\right)$ & $0.043^{3}$ & 0.043 \\
\hline $\bar{\theta}$ & .8354 & .8356 & .8267 & .8258 & average size ${ }^{2}$ & $58851^{3}$ & 58851 \\
\hline$\gamma$ & .97 & .968 & .98 & .964 & $\%$ firms $\leq 90 \%$ size & $71 \%^{3}$ & $70 \%$ \\
\hline$F^{1}$ & .013 & .013 & .010 & .012 & quarterly turnover & $3.67 \%^{3}$ & $3.75 \%$ \\
\hline$w_{0}^{1}$ & n.a. & n.a. & .19 & .33 & fraction of negative profits & $37 \%^{4}$ & $42 \%$ \\
\hline$\delta_{k}$ & .035 & .035 & .035 & .03 & $\frac{i_{t}}{k_{t}}$ & $0.145^{5}$ & 0.140 \\
\hline$\sigma_{\theta}$ & .0015 & .002 & .01 & .0182 & $\operatorname{std}\left(\frac{i_{t}}{k_{t}}\right)$ & $0.139^{5}$ & 0.095 \\
\hline$\rho_{\theta}$ & .98 & .98 & .7 & .7 & $\operatorname{corr}\left(\frac{i_{t}}{k_{t}}, \frac{i_{t-1}}{k_{t-1}}\right)$ & $0.239^{5}$ & 0.139 \\
\hline$\tau_{l}$ & n.a. & n.a. & 0 & 0 & (imperfect enforceability) & & \\
\hline$\tau_{k}$ & n.a. & n.a. & .679 & .679 & $\frac{d e b t}{a s s e t s}$ & $0.3^{6}$ & 0.32 \\
\hline$r$ & .01 & .01 & .01 & .01 & quarterly real interest rate & $1 \%$ & $1 \%$ \\
\hline
\end{tabular}

I: Industry with no constraint. II: Industry with only the irreversibility constraint. III: Industry with only the financing constraint. IV: Industry with both constraints. 1: Both $F$ and $w_{0}$ are expressed as fractions of the average size of fixed capital of a financially unconstrained firm. 2: Size in terms of fixed assets. 3: Moments computed using the aggregate data for the SIC34 sector. 4: Moments computed using the Worldscope Database. 5: Compustat data from Gomes (2001). 6: US corporate sector. 
Table 5: Simulated statistics

\begin{tabular}{|c|c|c|c|c|c|}
\hline & Empirical data & \multicolumn{4}{|c|}{ Simulated data ${ }^{3}$} \\
\hline & & $\begin{array}{l}\text { Both } \\
\text { constraints }\end{array}$ & $\begin{array}{l}\text { Only the } \\
\text { financing } \\
\text { constraint }\end{array}$ & $\begin{array}{l}\text { Only the } \\
\text { irreversibility } \\
\text { constraint }\end{array}$ & $\begin{array}{l}\text { No } \\
\text { constraint }\end{array}$ \\
\hline st.dev. Sales ${ }^{2}$ & 0.0429 & 0.0434 & 0.0449 & 0.0482 & 0.0424 \\
\hline$\frac{\text { st.dev.(deliveries) }}{\text { st.dev.(sales) }}$ & $1.38-1.16^{1}$ & 1.26 & 1.40 & 1.26 & 1.36 \\
\hline$\frac{\text { st.dev. }(\text { fixed capital })}{\text { stdev (sales) }}$ & $0.41^{1}$ & 0.37 & 0.72 & 0.93 & 1.05 \\
\hline$\frac{\text { st.dev. (deliveries })}{\text { st.dev }(\text { fixed capital })}$ & $2.79^{1}$ & 3.42 & 1.94 & 1.35 & 1.29 \\
\hline \multicolumn{6}{|c|}{$\operatorname{corr}\left(\right.$ deliveries $_{t} /$ sales $_{t}$, sales $\left._{t}\right)$} \\
\hline All periods & $0.18^{* *}$ & 0.24 & 0.33 & 0.28 & 0.33 \\
\hline Below trend & $0.28^{* *}$ & 0.28 & 0.24 & 0.22 & 0.29 \\
\hline Above trend & 0.03 & 0.13 & 0.31 & 0.26 & 0.29 \\
\hline Decrease in sales & $0.23^{*}$ & 0.30 & 0.21 & 0.16 & 0.25 \\
\hline Increase in sales & 0.12 & 0.04 & 0.27 & 0.24 & 0.23 \\
\hline $\begin{array}{l}\% \text { of binding } \\
\text { financing constraint }\end{array}$ & $\mathrm{N} / \mathrm{A}$ & $39 \%$ & $43 \%$ & $0 \%$ & $0 \%$ \\
\hline $\begin{array}{l}\% \text { of binding } \\
\text { irreversibility constraint }\end{array}$ & $\mathrm{N} / \mathrm{A}$ & $29 \%$ & $0 \%$ & $36 \%$ & $0 \%$ \\
\hline $\begin{array}{l}\% \text { of both } \\
\text { constraints binding }\end{array}$ & $\mathrm{N} / \mathrm{A}$ & $9 \%$ & $0 \%$ & $0 \%$ & $0 \%$ \\
\hline
\end{tabular}

1.Based on yearly data. 2. Standard deviations of percentage deviations from the trend. 3. Despite simulate data are stationary, we apply the same Hodrick Prescott filter used on the empirical data, in order to ensure that similar frequencies are filtered. ${ }^{* *}$ significant at the $99 \%$ confidence level; *significant at the $95 \%$ confidence level. 
Table 6: Simulated statistics, input inventories

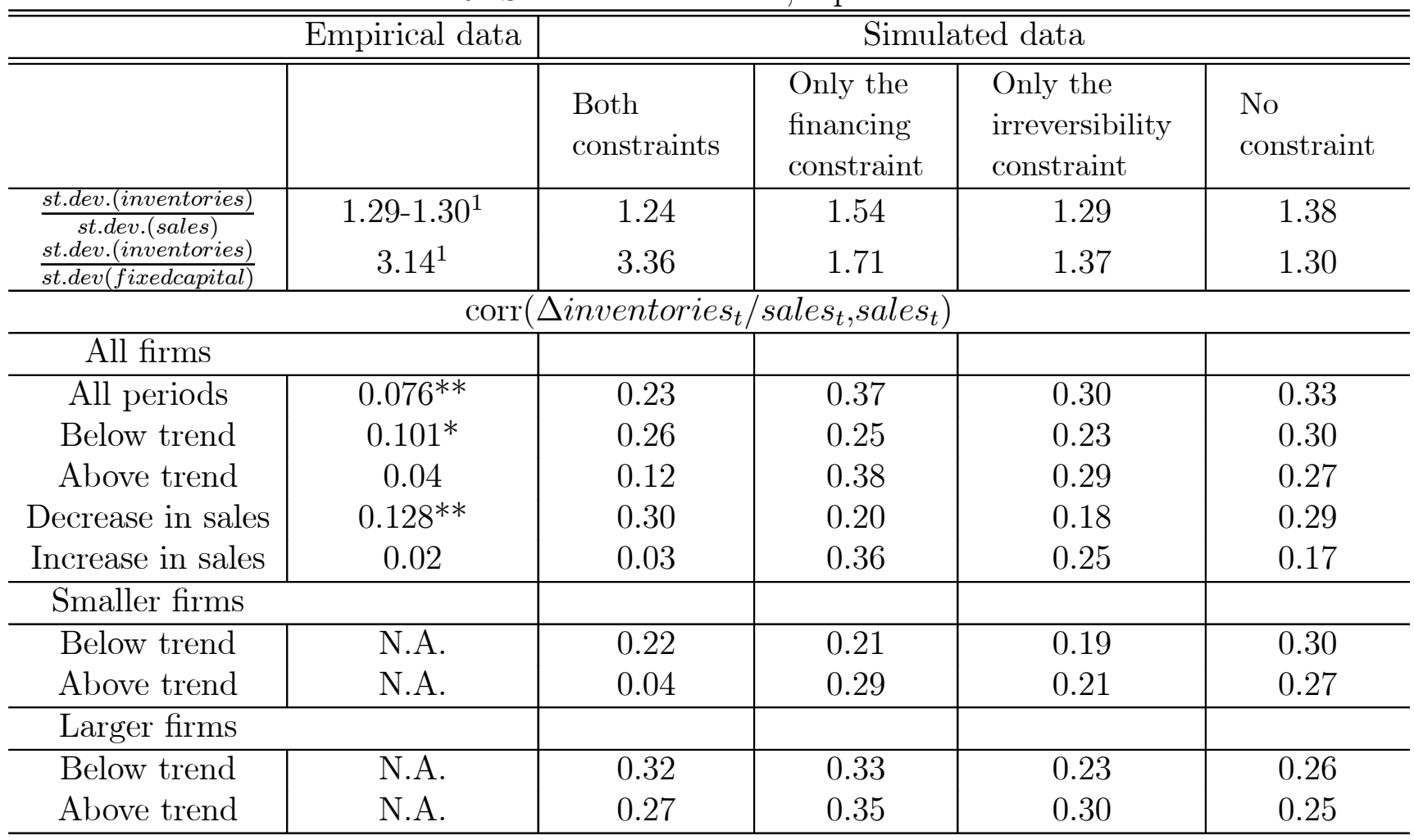

1. Based on yearly data. ${ }^{* *}$ significant at the $99 \%$ confidence level; ${ }^{*}$ significant at the $95 \%$ confidence level.

Table 7: Sales elasticity of deliveries

\begin{tabular}{|c|c|c|c|c|c|}
\hline & Empirical Data & \multicolumn{4}{|c|}{ Simulated Data } \\
\hline Increase in sales & & $\begin{array}{l}\text { Both } \\
\text { constraints }\end{array}$ & $\begin{array}{l}\text { Only the } \\
\text { financing } \\
\text { constraint }\end{array}$ & $\begin{array}{l}\text { Only the } \\
\text { irreversibility } \\
\text { constraint }\end{array}$ & $\begin{array}{l}\text { No } \\
\text { constraint }\end{array}$ \\
\hline$\frac{\partial d e l_{t+1}}{\partial s_{t}} \frac{s_{t}}{d e l_{t+1}}\left(1^{s t} \mathrm{qt}.\right)$ & 1.14 & 2.26 & 2.63 & 2.94 & 2.86 \\
\hline$\frac{\partial d e l_{t+1}}{\partial s_{t}} \frac{s_{t}}{d e l_{t+1}}\left(2^{\text {nd }}\right.$ qt. $)$ & 1.18 & 0.43 & 1.14 & 1.47 & 1.25 \\
\hline$\frac{\partial d e l_{t+1}}{\partial s_{t}} \frac{s t}{d e l_{t+1}}\left(3^{r d} \mathrm{qt}.\right)$ & 0.91 & 0.64 & 0.73 & 0.60 & 0.58 \\
\hline \multicolumn{6}{|l|}{ Decrease in sales } \\
\hline$\frac{\partial d e l_{t+1}}{\partial s_{t}} \frac{s_{t}}{d e l_{t+1}}\left(1^{s t} \mathrm{qt}.\right)$ & 1.15 & 2.17 & 2.64 & 2.98 & 3.01 \\
\hline$\frac{\partial d e l_{t+1}}{\partial s_{t}} \frac{s_{t}}{d e l_{t+1}}\left(2^{n d}\right.$ qt. $)$ & 1.66 & 0.84 & 0.76 & 1.05 & 1.23 \\
\hline$\frac{\partial d e l_{t+1}}{\partial s_{t}} \frac{s t}{d e l_{t+1}}\left(3^{r d}\right.$ qt. $)$ & 1.98 & 0.95 & 0.86 & 0.81 & 0.56 \\
\hline \multicolumn{6}{|l|}{ Decrease/increase } \\
\hline 1st quarter & 1.01 & 0.96 & 1.00 & 1.01 & 1.05 \\
\hline 2nd q. & 1.41 & 1.98 & 0.67 & 0.72 & 0.98 \\
\hline 3rd q. & 2.17 & 1.48 & 1.17 & 1.36 & 0.98 \\
\hline
\end{tabular}


Table 8: Irreversibility and output volatility

\begin{tabular}{l|c|c|c|c|c|c}
\hline \hline & \multicolumn{3}{|c|}{ Set of parameters 1 } & \multicolumn{3}{c}{ Set of parameters 2 } \\
\hline \hline & $\begin{array}{l}\text { Both } \\
\text { constraints }\end{array}$ & $\begin{array}{c}\text { Only the } \\
\text { financing } \\
\text { constraint }\end{array}$ & $\Delta \%$ & $\begin{array}{l}\text { Only the } \\
\text { irreversibility } \\
\text { constraint }\end{array}$ & $\begin{array}{l}\text { No } \\
\text { constraint }\end{array}$ & $\Delta \%$ \\
\hline st.dev. Sales & 0.0434 & 0.0939 & $116 \%$ & 0.0482 & 0.0563 & $17 \%$ \\
$\frac{\text { st.dev.(deliveries) }}{\text { st.dev.(sales) }}$ & 1.26 & 1.33 & $5.5 \%$ & 1.26 & 1.33 & $5.8 \%$ \\
$\frac{\text { st.dev.(fixed capital) }}{\text { st.dev.(sales) }}$ & 0.37 & 0.73 & $97 \%$ & 0.93 & 1.04 & $11.3 \%$ \\
$\frac{\text { st.dev.(deliveries) }}{\text { st.dev.(fixed capital) }}$ & 3.42 & 1.84 & $-46 \%$ & 1.35 & 1.28 & $-4.9 \%$ \\
\hline \hline
\end{tabular}

Set of parameters 1: parameters used in the benchmark calibration of the industry with both constraints. Set of parameters 2: parameters used in the benchmark calibration of the industry with only the irreversibility constraints. 